\title{
Synthesis, Characterization and Biocompatibility of a Multifunctional Gold Nanoparticle System for the Delivery of Single-Stranded RNA to Lymphocytes
}

\author{
Raveen Parboosing ${ }^{\mathrm{a}, \star}$, Thavendran Govender ${ }^{\mathrm{b}}$, Glenn E.M. Maguire ${ }^{\mathrm{b}}$ and Hendrik G. Kruger ${ }^{\mathrm{b}}$ \\ ${ }^{a}$ Department of Virology, University of KwaZulu-Natal/National Health Laboratory Service, Durban, South Africa. \\ ${ }^{b}$ Catalysis and Peptide Research Unit, University of KwaZulu-Natal, Durban, South Africa.
}

Received 18 January 2017, revised 12 September 2017, accepted 13 October 2017.

\begin{abstract}
The use of RNA macromolecules as therapeutic agents for HIV and other infectious diseases is promising but limited by suboptimal delivery to the target site. With HIV infection, this is particularly challenging since lymphocytes are particularly difficult to transfect. This paper describes an innovative strategy for the intracellular delivery of a novel single-stranded RNA (oligoribonucleotide) with putative anti-HIV activity. This strategy is based on a PEGylated gold nanoparticle scaffold covalently linked to the thiol-modified oligoribonucleotide via a cleavable $\mathrm{N}$-succinimidyl 3-(2-pyridyldithio) propionate (SPDP) linker molecule. The nanoparticle was then coated with a cationic polymer (polyethyleneimine) to facilitate cell entry and endosomal escape. A synthetic anti-CD4 cyclic targeting peptide was attached to the polyethyleneimine-coated nanoparticle via an SPDP linker molecule, in an attempt to enhance uptake and selectivity. Synthesis, characterization, SPDP and RNA loading, cytotoxicity and antiviral activity of the nanoparticle are described. Approximately 45000 strands of RNA were taken up per lymphocyte. Uptake was limited by relatively inefficient loading of RNA onto the gold nanoparticle surface $\left(1\right.$ strand per $4.8 \mathrm{~nm}^{2}$ of nanoparticle surface area) and significant aggregation of the nanoparticle in physiological solutions. No antiviral activity was demonstrated, possibly due to insufficient intracytoplasmic delivery of the RNA.
\end{abstract}

KEYWORDS

Gold nanoparticle, polyethyleneimine, transfection, RNA delivery.

\section{Introduction}

Various strategies exist for the use of RNA macromolecules as therapeutic agents for HIV and other infectious and noninfectious diseases. These strategies include RNA interference (RNAi), ribozymes, aptamers, siRNA, microRNAs, antisense oligonucleotides and steric-blocking oligonucleotides. ${ }^{1-3}$ However, the major impediment to RNA therapeutics is inefficient or unreliable delivery ${ }^{4}$ i.e. the safe passage of nonsequestered RNA, via the cell membrane, to its target site in the cytoplasm (or nucleus), at sufficient concentration, and for long enough, so as to exert the desired effect. ${ }^{5-6}$ The challenges with efficient delivery of nucleic acids include their short half-life in plasma, ${ }^{4-5,7-9}$ excretion by the kidneys, entrapment by the reticuloendothelial system, ${ }^{8}$ formation of aggregates with serum proteins, ${ }^{10}$ inability to cross biological membranes (including the cell membrane) because of strong negative charge ${ }^{10}$, and entrapment within vesicles within the cytoplasm. ${ }^{5,8}$ Lymphocytes, in particular, are difficult to transfect, ${ }^{11}$ which significantly limits the potential of RNA therapeutics for the treatment of HIV infection.

In an attempt to address these challenges, numerous methods have been developed for RNA delivery including viral vector based strategies, direct delivery by physical methods, chemical methods and nanotechnology approaches. However, finding a safe and effective method to achieve systemic and targeted delivery of RNA has remained an elusive goal, ${ }^{12-13}$ and siRNA delivery has only recently entered clinical trials. ${ }^{13}$

* To whom correspondence should be addressed. E-mail: parboosingr@ukzn.ac.za
This paper describes the synthesis, characterization and biological interaction of a multifunctional nanoparticle construct which attempts to address some of these challenges. The construct is based on the following facets (Fig. 1):

1. A gold nanoparticle scaffold to provide structural support

Assembly onto a gold nanoparticle scaffold facilitates orderly interaction between RNA, polyethyleneglycol (PEG) and polyethyleneimine. ${ }^{14-15}$ A similar system, based on inorganic gold particles and biodegradable polycations, has proven to be successful in safely and effectively delivering DNA, ${ }^{16-17}$ and more recently RNA, into cells. ${ }^{15}$ Gold nanoparticles are desirable nanocarriers because they are chemically stable and inert, biocompatible, have low cytotoxicity, can be synthesized in varying sizes with limited dispersity, have unique surface properties which allow for dense loading of multiple ligands, are amenable to multifunctionalization and have unique optical properties (that allow characterization and quantification) ${ }^{14-15,18-25}$ Furthermore, gold nanoparticles enhance the transfection efficiency of polyethyleneimine. ${ }^{26}$

2. PEG polymer to enhance biocompatibility

PEGylation reduces aggregation and non-specific interactions of gold nanoparticles with plasma proteins (i.e. promotes 'stealth' behaviour) and furthermore enhances their solubility, circulation time in the bloodstream, ${ }^{27}$ cytotoxicity profile and stability in physiological solutions. ${ }^{28-29}$ Insertion of a PEG 'spacer' molecule between the gold surface and the RNA also prevents reaction of the nanoparticle with the 


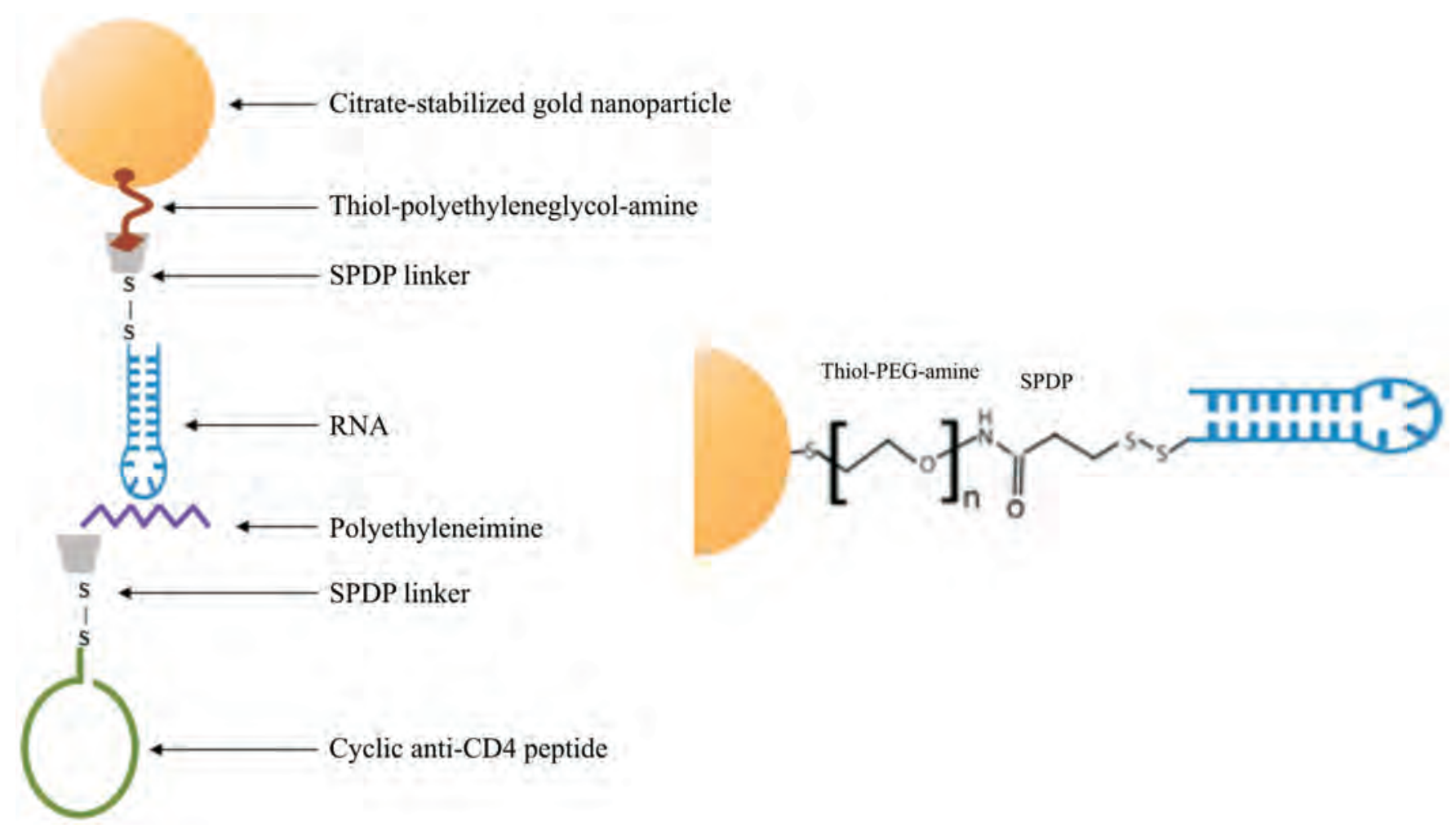

Figure 1 Schematic representation of multifunctional, PEGylated gold nanoparticle construct, showing RNA with putative anti-HIV activity, attached via an SPDP linker. The particle was coated with polyethyleneimine and bears a cyclic anti-CD4 peptide on the surface. The attachment of the SPDP linker to the thiol-PEG-amine and RNA is shown in more detail on the right. Portion of this figure are based on Lee et al. ${ }^{15}$

disulphide bond between the RNA and the linker molecule. ${ }^{15}$

3. A cleavable linker molecule (N-succinimidyl 3-(2-pyridyldithio) propionate or SPDP) to allow conjugation and release of the RNA

The thiol modified RNA was conjugated to the gold nanoparticle via a disulphide bond using the linker molecule SPDP. The disulphide bond is stable in the ionic, extracellular environment but is cleaved in the reductive conditions within the cytoplasm (thus releasing the RNA from the nanoparticle). ${ }^{15}$ More specifically, the disulphide bond is cleaved by intracellular glutathione, which is found in much higher concentration in intracellular vs. extracellular environments and this facilitates the selective intracellular release of the RNA. ${ }^{30}$

4. A single-stranded RNA molecule designed to inhibit HIV packaging

The sequence of the 16-mer single-stranded RNA is based on the packaging signal of HIV-1. It is designed to inhibit the encapsidation of the HIV genome by a decoy mechanism. ${ }^{31}$

5. Polyethyleneimine to enhance cell entry and facilitate endosomal escape

Polyethyleneimine, a synthetic cationic polymer, is the prototype non-viral gene delivery system and a popular choice for RNA transfection, since it protects RNA from enzymatic degradation, enhances cell entry and facilitates endosomal escape. ${ }^{32}$ Polyethyleneimine facilitates interaction between RNA and the cell membrane (both of which are negatively charged). Once the nanoparticle is taken up by endocytosis, polyethyleneimine facilitates release from the endosome via the 'proton sponge' effect. ${ }^{3-44}$ Polyethyleneimine then decondenses and separates from the nanoparticle, thus allowing release of the RNA. ${ }^{39,45}$ However, its use is somewhat limited by toxicity (probably due to unstable complexes in serum, resulting in release of unbound polyethyleneimine). ${ }^{32}$ Gold nanoparticles, by comparison, are far less toxic, but their use as transfection agents is hampered by endosomal entrapment and inefficient release of its nucleic acid cargo into the cytoplasm (due to high binding affinity between RNA and the surface of gold nanoparticles). ${ }^{46}$ Several studies have therefore sought to conjugate polyethyleneimine to gold nanoparticles in order to overcome the disadvantages of each i.e. to attenuate the toxicity of polyethyleneimine, and to enhance intracellular release of GNP systems. ${ }^{42,46-50}$ Additionally, polyethyleneimine has been successfully 'tagged' with peptides to further enhance transfection efficiency and to facilitate targeted delivery. ${ }^{51-55}$ Also, an experimental layer-by-layer electrostatic approach has been used to overcome aggregation issues ${ }^{42}$. We therefore postulated that the use of polyethyleneimine-coated GNP may overcome the barrier to successful delivery of RNA to the cytoplasm of hard-to-transfect lymphocytes.

6. Peptide functionalization

A synthetic cyclic peptide, designed to target the CD4 receptor, was attached to the surface of the gold nanoparticle via an SPDP linker molecule that facilitated conjugation to the branched polyethyleneimine. ${ }^{56}$ The design of the peptide was based on the amino acid sequence of an anti-CD4 monoclonal antibody. In previous studies, the peptide was found to bind to the CD4 receptor and furthermore inhibit cellular functions that depend on this receptor. ${ }^{57-61}$ In this paper, it is hypothesized that the presence of a targeting ligand on the surface of the gold nanoparticle would facilitate its selective uptake by CD4 lymphocytes via a receptor-mediated endocytosis pathway.

\section{Materials and Methods}

\subsection{Reagents}

All chemicals and reagents were obtained from Sigma-Aldrich (St. Louis, Missouri, USA), unless otherwise stated. Thiol-(PEG)- 
amine $\left(\mathrm{HSCH}_{2} \mathrm{CH}_{2} \mathrm{O}\left(\mathrm{CH}_{2} \mathrm{CH}_{2} 0\right)_{\mathrm{n}} \mathrm{CH}_{2} \mathrm{CH}_{2} \mathrm{NH}_{2}, \mathrm{MW}=1 \mathrm{KDa}\right)$ was obtained from Layson Bio (Arab, Alabama, USA). RNAse-free, HPLC-purified 5' thiol modified, 3' fluorescein labelled RNA was custom synthesized by Dharmacon (Pittsburgh, Pennsylvania, USA). RNAsecure Reagent and RPMI 1640 medium was obtained from Life Technologies (Grand Island, New York, USA). Heat-inactivated fetal calf serum was obtained from Biochrom GmbH, Berlin, Germany). The MT4 lymphocyte cell line was obtained from the NIH AIDS Reagent Program, Division of AIDS, NIAID, NIH, courtesy of Dr Douglas Richman. Virus stock (HIV-1 IIIB) was obtained through the NIH AIDS Reagent Program, Division of AIDS, NIAID, NIH: HTLV-IIIB/H9 from Dr Robert Gallo. ${ }^{62-64}$

\subsection{Synthesis}

\subsubsection{Synthesis of Gold Nanoparticle}

Gold nanoparticles (diameter 30-40 nm) were synthesized using the well-described method of Turkevich, in which chloroauric acid $\left(\mathrm{HAuCl}_{4} \cdot 3 \mathrm{H}_{2} \mathrm{O}\right)$ is reduced by trisodium citrate $\left(\mathrm{Na}_{3} \mathrm{C}_{6} \mathrm{H}_{5} \mathrm{O}_{7} \cdot 2 \mathrm{H}_{2} \mathrm{O}\right){ }^{65,68}$ Briefly, $500 \mathrm{~mL}$ of a $1 \mathrm{mM}$ solution of chloroauric acid in double-distilled water was mechanically stirred and brought to a vigorous boil under reflux. Then $50 \mathrm{~mL}$ of $19.5 \mathrm{mM}$ trisodium citrate was rapidly added to the boiling solution. The colour of the solution changed from dark purple to wine red and the reaction was continued for a further $15 \mathrm{~min}$. The solution was allowed to cool to room temperature and stored at $4{ }^{\circ} \mathrm{C}$. All glassware was thoroughly washed with aqua regia, rinsed with double-distilled water and oven-dried overnight prior to use. The size and concentration of the gold nanoparticles was determined by UV-vis spectrophotometry using the method of Haiss. ${ }^{69}$ The concentration of the gold nanoparticle solution was adjusted to $\sim 30 \mathrm{nM}$ and stored at 2-8 ${ }^{\circ} \mathrm{C}$ until use.

\subsubsection{PEGylation of Gold Nanoparticle}

The heterobifunctional polymer thiol-PEG-amine contains a thiol group that reacts readily with the citrate-capped surface of the gold nanoparticle, and an amine group that attaches to $N$-hydroxysuccinimide ester of the SPDP linker in the next step. The thiol-PEG-amine was reacted with the gold nanoparticle using the same number of moles of PEG per $\mathrm{nm}^{2}$ surface area of gold nanoparticle as Anderson's group. ${ }^{15}$ In a typical reaction, $32 \mathrm{mg}$ of thiol-PEG-amine was added to $100 \mathrm{~mL}$ gold nanoparticle solution $(\sim 0.5 \mathrm{nM})$ and incubated at $25^{\circ} \mathrm{C}$ for $12 \mathrm{~h}$ with constant mechanical stirring. Tween- $20^{\mathrm{TM}}$ at a concentration of $0.01 \%(\mathrm{v} / \mathrm{v})$ was added to the solution at the beginning of the reaction to prevent adherence of the nanoparticles to the surface of the reaction vessel. The particles were washed four times by centrifugation at approximately $20000 \times g$, followed by removal of the supernatant and re-dispersion in PBS containing $0.01 \%$ Tween- $20^{\mathrm{TM}}$. Re-dispersion was aided by vortexing and bath sonication for approximately $10 \mathrm{~s}$ each. The absence of aggregates was confirmed by visual inspection and by light microscopy. Successful PEGylation was confirmed by the colloidal stability test. ${ }^{70}$ Briefly, bare gold nanoparticles aggregate and form a purplish solution, while PEGylated nanoparticles retain their wine red colour when exposed to highly saline conditions (10x phosphate buffered saline). Furthermore, PEGylated gold nanoparticles migrate differently compared to bare gold nanoparticles on gel electrophoresis, due to loss of surface charge upon PEGylation. See Supplementary Material (Appendix A) for further details on the colloidal stability test and gel electrophoresis. The size and concentration of the $\mathrm{NH}_{2}$-PEG- gold nanoparticles was determined by UV-vis spectrophotometry. ${ }^{15,69}$ The solution was stored at $4^{\circ} \mathrm{C}$ until ready for use.

\subsubsection{Addition of the Linker Molecule (SPDP) to PEGylated Gold Nanoparticle}

SPDP was reacted with the PEGylated gold nanoparticle solution using the same number of moles of SPDP per $\mathrm{nm}^{2}$ surface area of gold nanoparticle as Anderson's group. ${ }^{15}$ In a typical reaction, $500 \mu \mathrm{L}$ SPDP in PBS ( $3 \mathrm{mM}$, solubilized with $10 \%$ DMSO) was incubated for $40 \mathrm{~min}$ with $500 \mu \mathrm{L} \mathrm{NH}_{2}$-PEG-AuNPs in PBS $\left(2.7 \mathrm{nM}\right.$, with $0.01 \% \mathrm{~T}$ Tween-20 $\left.0^{\mathrm{TM}}, \mathrm{pH} 7.4\right)$ at $25^{\circ} \mathrm{C}$ with vigorous vortexing. The unconjugated SPDP was removed by repeated centrifugation and re-dispersion as described for the PEGylation reaction above.

\subsubsection{RNA Conjugation}

In this step, the $5^{\prime}$ thiol of the RNA reacts with the 2-pyridylthio group of SPDP. ${ }^{15}$ The RNAse-free, HPLC-purified $5^{\prime}$ thiol modified, $3^{\prime}$ fluorescein labelled RNA construct (Dharmacon, Pittsburgh Pennsylvania, USA) was reduced ${ }^{71}$ and de-protected ${ }^{72}$ as recommended by the manufacturer. The sample was dried using a centrifugal evaporator (miVac DNA Sample Concentrator, Genevac, Stone Ridge, New York, USA) and re-suspended in Borate Buffered Saline (BBS) with $0.01 \%$ Tween-20 ${ }^{\mathrm{TM}}(\mathrm{pH}$ 8.3-8.5). The BBS was incubated with RNAsecure Reagent (Life Technologies, Grand Island, New York, USA) for $10 \mathrm{~min}$ at $60^{\circ} \mathrm{C}$, to remove potential RNAses prior to use. The RNA was quantified by obtaining an absorbance at $260 \mathrm{~nm}$. The software provided by the manufacturer allows an adjustment to be made to account for the effect of fluorescein on the absorbance reading (BioSpec Nano, Shimadzu Corporation, Kyoto, Japan). The SPDP-NH $\mathrm{N}_{2}$-PEG-gold nanoparticle was re-suspended in $2 \mathrm{~mL}$ borate buffered saline containing the RNA (15 $\mu \mathrm{M}$ RNA, $2.5 \mathrm{M}$ $\mathrm{NaCl}$ solution, $30 \mathrm{mM}$ borate, $\mathrm{pH} 8.5,0.01 \%$ Tween-20 ${ }^{\mathrm{rm}}$ ) and incubated at $25^{\circ} \mathrm{C}$ for $40 \mathrm{~h}$ with vigorous vortexing. The particles were then washed four times by centrifugation at $15700 \times g$ for $15 \min ^{42}$ at $4{ }^{\circ} \mathrm{C}^{73}$, removal of the supernatant and re-dispersion in sterile phosphate buffered saline $(137 \mathrm{mM} \mathrm{NaCl}$ solution, $10 \mathrm{mM}$ phosphate, $2.7 \mathrm{mM} \mathrm{KCl}, \mathrm{pH}$ 7.4, $0.01 \%$ Tween-20 ${ }^{\mathrm{TM}}$ ). In the final wash, the nanoparticle solution was adjusted to a concentration of $2 \mu \mathrm{M}$ and re-suspended in $10 \mathrm{mM} \mathrm{NaCl}$ solution. Re-dispersion was aided by vortexing and bath sonication for approximately $10 \mathrm{~s}$ each. The RNA was protected from light.

\subsubsection{Polyethyleneimine Coating}

In this step, branched polyethyleneimine with an average molecular weight of $25 \mathrm{KDa}$ was added at a final concentration of $1.0 \mathrm{mg} \mathrm{mL}^{-1}$ to a stirring solution of RNA-gold nanoparticles in $10 \mathrm{mM} \mathrm{NaCl}$ solution. This was then incubated at room temperature for $30 \mathrm{~min}$, in order to form a polyelectrolyte layer around the outer surface of the gold nanoparticle. The nanoparticles were then washed by centrifugation and re-dispersion in $10 \mathrm{mM}$ $\mathrm{NaCl}$ solution. ${ }^{42}$

\subsubsection{Peptide Conjugation}

A targeting peptide was attached to the surface of the gold nanoparticle. The sequence of the peptide was derived from the variable domains of an anti-CD4 monoclonal antibody and has been previously published..$^{57-61}$ The peptide was synthesized by routine FMoc (9-fluorenylmethoxycarbonyl) Solid Phase Synthesis $^{74-78}$ on a CEM microwave peptide synthesizer ${ }^{79-80}$ and cyclized by on-resin iodine-oxidation of cysteine residues close to the $\mathrm{N}$ and C termini of the peptide. ${ }^{60,81}$ An AAC 'tail' at the end of the peptide facilitated conjugation to the polyethyleneimine 
via an SPDP linker molecule. ${ }^{56}$ See Supplementary Material (Appendix B) for further details of the peptide and its synthesis.

\subsection{Characterization}

\subsubsection{Size, Polydispersity, Zeta-potential and Concentration}

Size, polydispersity, zeta-potential and concentration of the nanoparticles were determined at the end of each step of the synthesis process. The size and concentration of the gold nanoparticles was determined by UV-vis spectrophotometry using the method of Haiss. ${ }^{69}$ The hydrodynamic diameter, zeta-potential and polydispersity were determined using the Malvern Zetasizer (Malvern Instruments, Worcestershire, United Kingdom). A general-purpose analysis model was selected for size measurements. The angle of detection was $175^{\circ}$. For zeta potential measurements, the Smoluchowski F(ka) value of 1.5 was used for the Henry's equation. For both size and zeta potential, the automatic setting was selected to allow the software to determine the optimal duration of measurement.

\subsubsection{Visualization of Nanoparticles by Electron Microscopy}

For visualization of gold nanoparticles, a drop of the solution was placed on a copper grid and allowed to dry and then visualized on a JEOL 2100 High Resolution Transmission Electron Microscope. ${ }^{82}$ A representative image was imported into Image J and transformed into a monochrome 8-bit format. The scale of the image was set and the 'brightness' threshold adjusted appropriately. The mean, range and standard deviation of the diameter of at least 30 particles was determined using a manual particle sizing method. ${ }^{83}$

\subsubsection{Aggregation}

To study the factors associated with aggregation of polyethyleneimine-coated nanoparticles, the final product was spun down and re-suspended in solutions adjusted to a range of $\mathrm{pH}$ values and with FBS (at varying percentages $0,5,10$ and $20 \%$ ) and Tween- $20^{\mathrm{TM}}$. Aggregation was quantified visually by dispensing the aliquots of the various nanoparticle solutions into the well of a clear flat-bottomed microtitre plate, which were then viewed under a Leica DMIL light microscope (Leica, Wetzlar, Germany) at $\times 200$ magnification. Images were captured on a Zeiss Axiocam 105 camera (Carl Zeiss, Oberkochen, Germany). The images were imported into Image J software in an 8-bit grayscale format, and the black: white threshold was adjusted by the maximum entropy method. ${ }^{84}$ The number of black pixels (representing aggregated nanoparticles) was enumerated by Image J software and expressed as a percentage of the total number of pixels. This percentage corresponds to the degree of aggregation visible by light microscopy. The method was validated by preparing serial dilutions of an aggregated nanoparticle and generating a standard curve of percentage aggregation visible by microscopy vs. percentage aggregation by serial dilution. See Supplementary Material (Appendix C) for further details of the method.

\subsection{Loading}

\subsubsection{SPDP Loading}

The loading (i.e. the mean number of SPDP linker molecules per $\mathrm{nm}^{2}$ surface area of GNP) was determined by a cleave-andanalyze approach. First, a reducing agent (in this case excess dithiothreitol or DTT) was used to cleave the pyridine-2-thione moiety from each molecule of SPDP conjugated onto the surface of the gold nanoparticle. The concentration of pyridine-2-thione (assumed to be equivalent to that of SPDP) was then determined by measuring its absorbance at $343 \mathrm{~nm} .{ }^{85}$ Excess (non-conjugated) SPDP was removed by repeated centrifugation and washing, prior to measurement. See Supplementary Material (Appendix D) for further details of the method and calculations.

\subsubsection{RNA Loading}

The number of strands of RNA per nanoparticle, prior to polyethyleneimine coating was determined using a detachand-analyze approach, prior to coating with polyethyleneimine. ${ }^{15}$ Aliquots of the RNA-gold nanoparticle ( $1 \mathrm{~mL}$ each) were incubated for $30 \mathrm{~min}$ at $30^{\circ} \mathrm{C}$ with either $0.05 \mathrm{M}$ DTT solution in PBS (pH 7.4, $0.01 \%$ Tween-20 ${ }^{\mathrm{rM}}$ ) or PBS (pH 7.4, $0.01 \%$ Tween-20 ${ }^{\mathrm{TM}}$ ) alone without DTT (as a control). DTT is a reducing agent that cleaves disulphide bonds thus releasing RNA from the surface of the gold nanoparticle. Fluorescence signals from RNA prior to release are quenched by the gold nanoparticle surface plasmon resonance. A $200 \mu \mathrm{L}$ aliquot was taken for fluorescence measurement after incubation with DTT and PBS control. The aliquot was centrifuged at $15700 \times g$ for $15 \mathrm{~min}$ at $4{ }^{\circ} \mathrm{C}$ to pellet the gold nanoparticles thus avoiding quenching effects. Fluorescence of the supernatant was then measured on a Glomax Multimode Detection System, using the Blue filter (Excitation: 490 nm, Emission: 510-570 nm) (Promega Corporation Madison, Wisconsin, USA). The concentration of RNA was calculated by plotting the difference in fluorescence (DTT aliquot less control (PBS only) aliquot) on a standard curve of fluorescently labelled RNA concentration $v$ s. relative fluorescence units. ${ }^{86}$ See Supplementary Material (Appendix E) for further details of the method and calculations.

\subsection{Cell Uptake}

Uptake of the nanoparticle by MT4 lymphocytes was assessed by electron microscopy, fluorometry, flow cytometry, and fluorescent and light microscopy.

\subsubsection{Cells}

MT4 lymphocytes (obtained from the NIH AIDS Reagent Program, Division of AIDS, NIAID, NIH from Dr Douglas Richman) were grown at $37^{\circ} \mathrm{C}$ in $5 \% \mathrm{CO}_{2}$ in RPMI 1640 medium (GIBCO/Life Technologies, Grand Island, New York, USA) containing sodium bicarbonate and L-glutamine, supplemented with $10 \%$ heat-inactivated fetal calf serum (Biochrom $\mathrm{GmbH}$, Berlin, Germany). Cells were split 1:10 every 3 days and regularly monitored for viability and contamination. Cells were used at the exponential phase of growth and with viability at least $95 \%$. The Countess ${ }^{\mathrm{TM}}$ Automated Cell Counter (Life Technologies, Grand Island, New York, USA) was used to determine cell counts and viability.

\subsubsection{Electron Microscopy}

To study uptake of gold nanoparticles, $250 \mu \mathrm{L}$ of the final nanoparticle product was added to MT4 lymphocytes $(5 \mathrm{~mL}$ at $3 \times 10^{5}$ cells $\mathrm{mL}^{-1}$ in a $25 \mathrm{~cm}^{2}$ cell culture flask) and incubated overnight at $37^{\circ} \mathrm{C}$ with $5 \% \mathrm{CO}_{2}$. The cell suspension was then centrifuged for $5 \mathrm{~min}$ at $300 \times g$ to form a pellet. The culture medium was removed without disturbing the pellet and replaced with excess $2.5 \%$ glutaraldehyde. The mixture was incubated at room temperature for $10 \mathrm{~min}$, spun again and then resuspended in fresh glutaraldehyde and incubated at $4{ }^{\circ} \mathrm{C}$ overnight. The sample was then washed 3 times with phosphate buffer and incubated for $1 \mathrm{~h}$ with $0.5 \%$ osmium tetroxide. The specimen was thereafter washed $3 x$ with phosphate buffer, dehydrated with increasing concentrations of acetone, infil- 
trated with epoxy resin, embedded in fresh resin and then polymerized in an oven for $8 \mathrm{~h}$ at $70^{\circ} \mathrm{C}$. Several sections were cut and visualized on a JEOL 2100 High Resolution Transmission Electron Microscope. ${ }^{87}$

\subsubsection{Flow Cytometry}

MT4 lymphocytes (50 000 cells/well) were suspended in wells of a microtitre plate with $200 \mu \mathrm{L}$ complete RPMI. The cells were then incubated overnight with $25 \mu \mathrm{L}$ of untreated control (RPMI only), RNA control (10 $\mu \mathrm{M}$ RNA only), uncoated nanoparticle, without polyethyleneimine (3 nM), complete nanoparticle $(3 \mathrm{nM})$ and $10 \%$ DMSO (dead cell control). The cells were then harvested, washed twice by gentle centrifugation, fixed with paraformaldehyde, resuspended in PBS and stored at $4{ }^{\circ} \mathrm{C}$ until analysis by flow cytometry (within $24 \mathrm{~h}$ ). Uptake was determined on BD FACSCanto ${ }^{\mathrm{TM}}$ II (BD Biosciences San Jose, CA, USA) instrument. Uptake of RNA was quantified as the percentage of cells that were fluorescent. ${ }^{88}$

\subsubsection{Fluorescent Microscopy}

Cells were treated, harvested and washed as for flow cytometry and then added to poly-L-lysine-coated microscope slides. The slides were fixed with paraformaldehyde and then viewed and photographed under a Nikon fluorescent microscope (Nikon, Tokyo, Japan). ${ }^{89}$

\subsubsection{Fluorometry}

Flow cytometry and epifluorescent microscopy may fail to detect uptake if the fluorescent signal per cell is below the limit of detection for either technique. This may occur if only a small number of gold nanoparticles are taken up per cell, for example, or if there is quenching of the fluorescent signal of the fluorescein-tagged intracellular RNA. In this case, the fluorescent signal may be amplified by examining the cumulative uptake of a large number of cells (e.g. $\geq 10$ million cells). To achieve this, $10 \times 10^{6}$ cells in a cell culture flask were exposed to treatment and the cumulative fluorescent signal quantified by pelleting and lysing the entire volume of cells post-incubation. This method differentiates intracellular from extracellular RNA by thoroughly washing the cells post-incubation (to remove extracellular RNA, whether bound to nanoparticles or not). Furthermore, the method differentiates 'free' RNA vs. RNA bound to the surface of the gold nanoparticle, since the latter is removed by centrifugation prior to measurement. The details of the method are as follows:

MT4 lymphocytes were centrifuged at $200 \times \mathrm{g}$ and then re-suspended in colourless RMPI with $10 \%$ FCS at a concentration of $1 \times 106$ cells mL-1. The following nanoparticles and controls were sonicated and added to flasks containing the MT4 lymphocytes in $10 \mathrm{~mL} \mathrm{RPMI} / 10 \%$ FCS:

a. Buffer control: $200 \mu \mathrm{L}$ PBS

b. Complete nanoparticle: $200 \mu \mathrm{L}$

GNP-PEG-SPDP-RNA-polyethyleneimine nanoparticle $(\sim 3 \mathrm{nM})$

c. Uncoated nanoparticle (without polyethyleneimine) $200 \mu \mathrm{L}$ AuNP-PEG-SPDP-RNA nanoparticle $(\sim 3 \mathrm{nM})$

d. Free RNA: $200 \mu \mathrm{L}$ RNA $(\sim 10 \mu \mathrm{M})$

The RNA and nanoparticles were incubated with the cells for varying periods $(1,6,12$ and $24 \mathrm{~h})$. At the end of the incubation period, the cells were washed 4 times (by centrifugation and resuspension in PBS). An aliquot of the supernatant from the final wash was stored for measurement of residual background fluorescence. The cell pellets were frozen at $-70{ }^{\circ} \mathrm{C}$ for at least
$24 \mathrm{~h}$. The cells were then thawed at room temperature and lysed with CyQuant cell lysis buffer as per manufacturer's instructions (Invitrogen/Life Technologies, Grand Island, New York, USA). The sample was centrifuged at $15700 \times g$ for $15 \mathrm{~min}$ at $4{ }^{\circ} \mathrm{C}$ to pellet the gold nanoparticles which cause quenching of the fluorescence signal. The fluorescence of the supernatant was measured post-lysis. The background fluorescence was subtracted from this value and the number of RNA strands released per cell was quantified with the use of an RNA standard curve (See Supplementary Material (Appendix E) for detailed calculations).

\subsection{Cytotoxicity and Antiviral Activity}

\subsubsection{MTT Cytotoxicity (Methylthiazolyldiphenyl-tetrazolium Bromide) Assay}

The MTT assay was used to determine cytotoxicity (50\% inhibitory concentration, $\mathrm{IC}_{50}$ ), as previously described. ${ }^{90}$ Briefly, $10 \mu \mathrm{L}$ of nanoparticle solution from each stage of synthesis was added (in triplicate) to $90 \mu \mathrm{L}$ complete media in wells of a microtitre plate. The 'outer' wells of the plate were filled with PBS to avoid 'edge' effects. Serial 10-fold dilutions of the nanoparticles were made. No treatment was added to the last column, which served as the untreated control. Then $60 \mu \mathrm{L}$ of MT4 lymphocytes (at $6 \times$ $10^{5}$ cells $\mathrm{mL}^{-1}$ ) was added to each well. The plates were incubated for 5 days at $37^{\circ} \mathrm{C}$ in $5 \% \mathrm{CO}_{2}$ in a humidified incubator. At the end of the incubation period, $15 \mu \mathrm{L}$ of MTT salt $\left(7.5 \mathrm{mg} \mathrm{mL}^{-1}\right.$ dissolved in PBS by sonication) was added to each well using a multichannel pipette. The plate was incubated for $1 \mathrm{~h}$ at $37^{\circ} \mathrm{C}$ in a $\mathrm{CO}_{2}$ incubator. Then $100 \mu \mathrm{L}$ of media was removed without disturbing the cells. The cells were lysed and the formazan crystals solubilized with the addition $100 \mu \mathrm{L}$ of acidified Triton ${ }^{\mathrm{TM}} \mathrm{X}-100$ in isopropanol $(50 \mathrm{~mL}$ isopropanol with $3 \mathrm{~mL}$ Trito $^{\mathrm{TM}} \mathrm{n}-\mathrm{X} 100$ and $200 \mu \mathrm{L}$ hydrochloric acid). The plates were placed on a vibrating shaker for $10 \mathrm{~min}$. Absorbance was read on Glomax Absorbance Module (wavelength 540 and $690 \mathrm{~nm}$ ). The absorbance at $690 \mathrm{~nm}$ was subtracted from the absorbance at $540 \mathrm{~nm}$ and the results plotted on a graph. The $\mathrm{IC}_{50}$ was determined by linear extrapolation using the percentage cytotoxicity at each concentration $(\%$ cytotoxicity at a given concentration $=$ absorbance at that concentration $\div$ absorbance of untreated cells $\times 100$ ). Untreated cells (i.e. cells treated with PBS only) were deemed to have $100 \%$ viability. Growth medium without phenol red was used in the assay to improve sensitivity of absorbance readings. ${ }^{91}$

\subsubsection{Antiviral Assay}

Stock virus was prepared by harvesting supernatant of HIV-infected MT4 lymphocytes at day 5 post-infection. The virus was titrated by conventional TCID methods and stored at $-80{ }^{\circ} \mathrm{C}$ until use..$^{0}$ The infectivity and cytopathic effect of the virus used in the assay was confirmed by ensuring that the viability of cells infected by HIV was at least 5 -fold less than that of mock-infected cells. ${ }^{90}$ All work involving HIV culture was performed in the appropriate biosafety conditions. ${ }^{92-93}$

The antiviral assay to assess the cytoprotective (antiviral) effect (50\% effective concentration, $\mathrm{EC}_{50}$ ) and selectivity index (SI) of the nanoparticle was performed as previously described..$^{90}$ The final nanoparticle solution $(10 \mu \mathrm{L})$ was added to $90 \mu \mathrm{L}$ complete media in 6 wells of a column of a microtitre plate. Serial 10-fold dilutions were made. No treatment was added to the last column, which served as the untreated control. Then $60 \mu \mathrm{L}$ of MT4 lymphocytes (at $6 \times 10^{5}$ cells $\mathrm{mL}^{-1}$ ) was added to all wells (except outer wells, to avoid edge effects). To assess cytotoxicity, 
$50 \mu \mathrm{L}$ of RPMI was added to each well in the 'upper' half of the plate (mock infection) while $50 \mu \mathrm{L}$ of $\mathrm{HIV}_{\text {ІІІв }}$ at 300 Tissue Culture Infective Dose (TCID) ${ }_{50}$ was added to the 'lower' half (HIV infection) to assess antiviral effect. The plates were incubated for 5 days at $37^{\circ} \mathrm{C}$ in $5 \% \mathrm{CO}_{2}$ in a humidified incubator. At the end of the incubation period, the MTT assay, as described above, was performed to assess toxicity in mock (uninfected) cells and cytoprotective effect in HIV-infected cells. The absorbance readings were plotted on a graph and the $\mathrm{IC}_{50}$ and $\mathrm{EC}_{50}$ were determined by linear extrapolation.

The $\mathrm{IC}_{50}$ was determined as described above. The percentage protection at each dilution was calculated as follows. ${ }^{90}$

Percentage protection at given concentration $=$

$100 \times(\mathrm{HT}-\mathrm{HC}) / \mathrm{Mc}-\mathrm{HC})$

where HT = average absorbance of treated, HIV infected cells at that concentration, $\mathrm{HC}=$ average absorbance of untreated, HIV infected cells, and $\mathrm{Mc}=$ average absorbance of untreated, mock infected cells

The selectivity index $=\mathrm{IC}_{50} / \mathrm{EC}_{50}$

Untreated, uninfected cells and untreated, HIV-infected cells were deemed to have $100 \%$ and $0 \%$ viability, respectively. ${ }^{90}$ AZT (Azidothymidine) was used as a control (which required simultaneous preparation and incubation of a separate plate, using the same reagents, cell preparation and virus stock).

\section{Results and Discussion}

\subsection{Characterization}

It was necessary to synthesize several batches of gold nanoparticles for the experiments in this paper. The mean core diameter of nanoparticles in all batches fell within the range 30-40 nm. Size, zeta potential and UV-vis absorption spectra (absorbance and $\ddot{e}_{\text {spr }}$ ) of the nanoparticle at each stage of synthesis are shown in Table 1 and Fig. 2. The average diameter in a typical batch, as measured by electron microscopy was $30.08 \mathrm{~nm}$ (range 19.07-47.44 nm, standard deviation $6.57 \mathrm{~nm}$ ). Nanoparticles from a typical batch are shown in Fig. 3. Addition of the cyclic peptide-SPDP conjugate to the gold nanoparticle solution resulted in extensive, irreversible macroscopic aggregation, precluding any further characterization, uptake or antiviral studies.

There was significant aggregation of the polyethyleneiminecoated nanoparticles when exposed to FBS (Figs. 4, 5 \& 7). The gold nanoparticles referred to in this experiment were studied in its entirety, i.e. with PEG, SPDP, RNA and polyethyleneimine coating, as described in the Synthesis section. Fig. 4 shows a dose response effect between the degree of aggregation and the percentage FBS in the medium. It is important to note that aggregation occurred even at $10 \%$ FBS (the typical concentration of serum used in cell culture media). Aggregation of

Table 1 Size, zetapotential and $\mathrm{IC}_{50}$ of gold nanoparticles.

\begin{tabular}{|c|c|c|c|c|}
\hline Particle & $\begin{array}{l}\lambda_{\max } \\
/ \text { size }\end{array}$ & $\begin{array}{c}\text { Size by DLS } \\
/ \mathrm{nm}\end{array}$ & $\begin{array}{l}\text { Zeta potential } \\
\quad / \mathrm{mV}\end{array}$ & $\begin{array}{l}\mathrm{IC}_{50} \\
/ \mathrm{nM}\end{array}$ \\
\hline Gold nanoparticle (GNP) & $\begin{array}{c}527 \\
(39 \mathrm{~nm})\end{array}$ & 37 & -21.4 & $0.56^{*}$ \\
\hline GNP-PEG & 530 & 76.6 & +5.37 & $>1.72$ \\
\hline GNP-PEG-SPDP & 530 & 73.9 & 0.895 & $>0.40$ \\
\hline GNP-PEG-SPDP-RNA & 530 & 78.1 & -7.6 & $>0.67$ \\
\hline GNP-PEG-SPDP-RNA-polyethyleneimine & 533 & $* *$ & 13.5 & $>0.67$ * \\
\hline
\end{tabular}

* Significant aggregation of the nanoparticle occurred in the cell culture medium.

** Measurement did not meet the quality criteria required for an acceptable determinaiton of size due to the polydispersity of the sample.

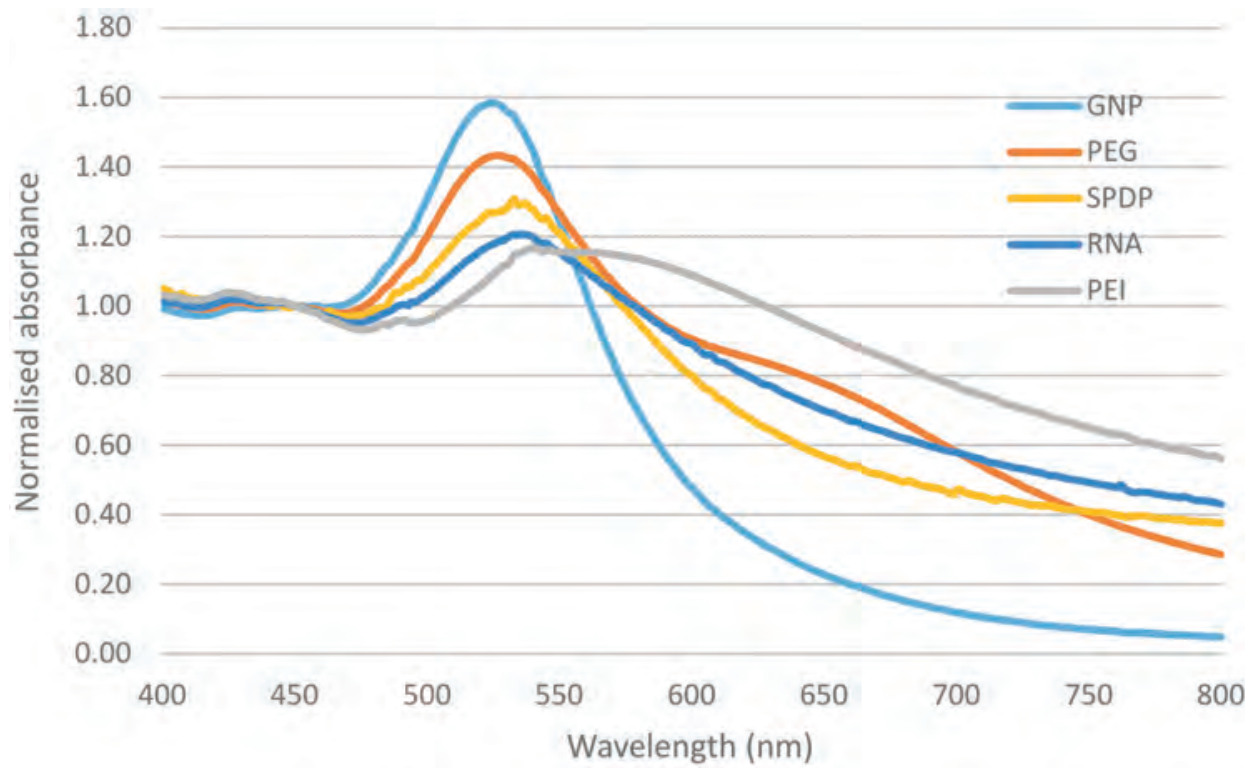

Figure 2 UV-vis spectra of the gold nanoparticle construct at various stages of synthesis. The raw data were downloaded from the BioSpec Nano instrument and plotted in Excel ${ }^{\mathrm{TM}}$. Absorbance values were normalized for differences in concentration by setting the absorbance at $450 \mathrm{~nm}$ to 1 for all samples. (GNP = bare gold nanoparticle and PEG = PEGylated gold nanoparticle, i.e. gold nanoparticle conjugated to thiol-PEG-amine and SPDP = SPDP linker conjugated to PEGylated gold nanoparticle and RNA = RNA conjugated to PEGylated gold nanoparticle via SPDP linker and PEI = polyethyleneimine-coated nanoparticle following RNA conjugation 

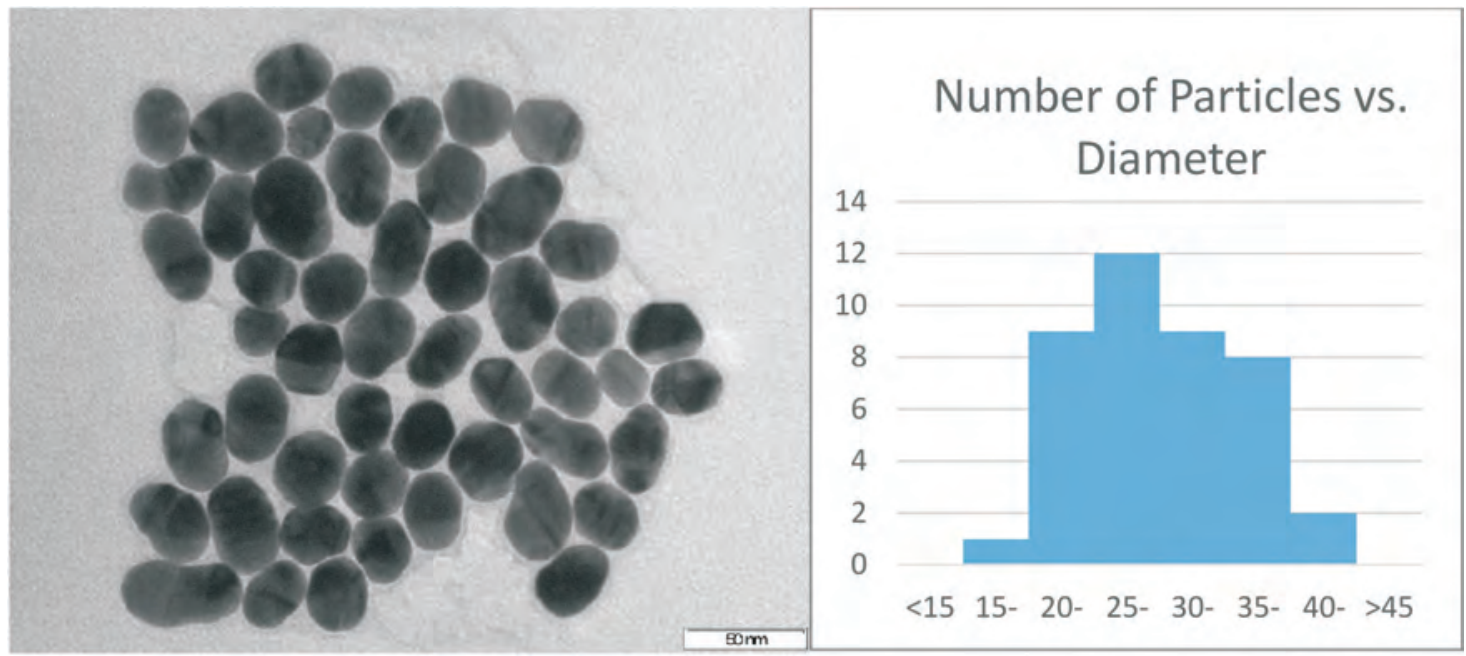

Figure 3 Electron micrograph of $\sim 30 \mathrm{~nm}$ diameter polyethyleneimine-coated gold nanoparticles. The distribution of the diameter of the particles is shown on the right.

nanoparticles was visible by light microscopy within a few minutes of exposure to cell culture medium and plateaued within $24 \mathrm{~h}$. Adjusting the $\mathrm{pH}$ of media to $\mathrm{pH}<5$ and $\mathrm{pH}>11$ (by addition of $10 \mathrm{mM}$ hydrochloric acid or sodium hydroxide, respectively) reversed the aggregation, while Tween- $20^{\mathrm{TM}}$ $(0.01 \%)$ did not. The presence of live cells did not have any effect on aggregation.

\subsection{Loading}

An average PEGylated gold nanoparticle was decorated with an average of 20350 SPDP linker molecules (or 2.6 SPDP molecules per $\mathrm{nm}^{2}$ nanoparticle surface area). This is in keeping with published data on the density of PEG molecules per $\mathrm{nm}^{2}$ nanoparticle surface area of gold nanoparticle (even if one assumes that SPDP binds to every available PEG on the surface of the nanoparticle). Estimates of PEG loading vary from $<1$ to $\sim 5$ PEG per $\mathrm{nm}^{2}$ nanoparticle surface area, depending on the molecular weight of the PEG, the shape and size of the nanoparticle and measurement method. ${ }^{28}$ In particular, the molecular weight (or length) of the PEG molecule drastically influences grafting density, possible due to steric hindrance with higher chain lengths, ${ }^{29}$ so that the density varies from 0.32 PEG $\mathrm{nm}^{-2}$ to 3.93 PEG nm${ }^{-2}$ for PEG as the molecular weight of the PEG decreases from 51400 to 2100 respectively. Therefore, the loading of SPDP is in keeping with these data (taking into account measurement errors and possibly a ratio other than 1:1 of SPDP conjugated to PEG).

On average, each nanoparticle contained $\sim 1050$ strands of RNA (or 1 strand per $\sim 4.8 \mathrm{~nm}^{2}$ of nanoparticle surface area), prior to polyethyleneimine coating. Therefore, on average there were 26 SPDP molecules per $10 \mathrm{~nm}^{2}$ nanoparticle surface area, and only $\sim 2$ (i.e. $8 \%$ ) of these were conjugated to RNA (assuming that RNA is conjugated to SPDP and not directly to the gold nanoparticle surface). By comparison, Anderson's group et al. ${ }^{15}$ found that there were $30-40$ strands of RNA per $15 \mathrm{~nm}$ diameter nanoparticle (or, by our calculations, approximately 1 strand of RNA per $18-24 \mathrm{~nm}^{2}$ of nanoparticle surface area), suggesting that the loading of RNA in their study was even less efficient. However, any comparisons must take into account that the RNA in Anderson's study was double rather than single-stranded, and that a different method of RNA quantification was used).

Increasing the concentration of RNA did not improve the loading. Typically, $<10 \%$ of the RNA added to the reaction mixture was conjugated to the gold nanoparticle and the rest remained unbound and was detectable in the supernatant. Although Lee et al. do not explicitly determine the proportion of RNA that conjugates to the $\mathrm{GNP}^{15}$ they provide sufficient data for the calculation to be made. In their study, only $6 \%$ of the RNA

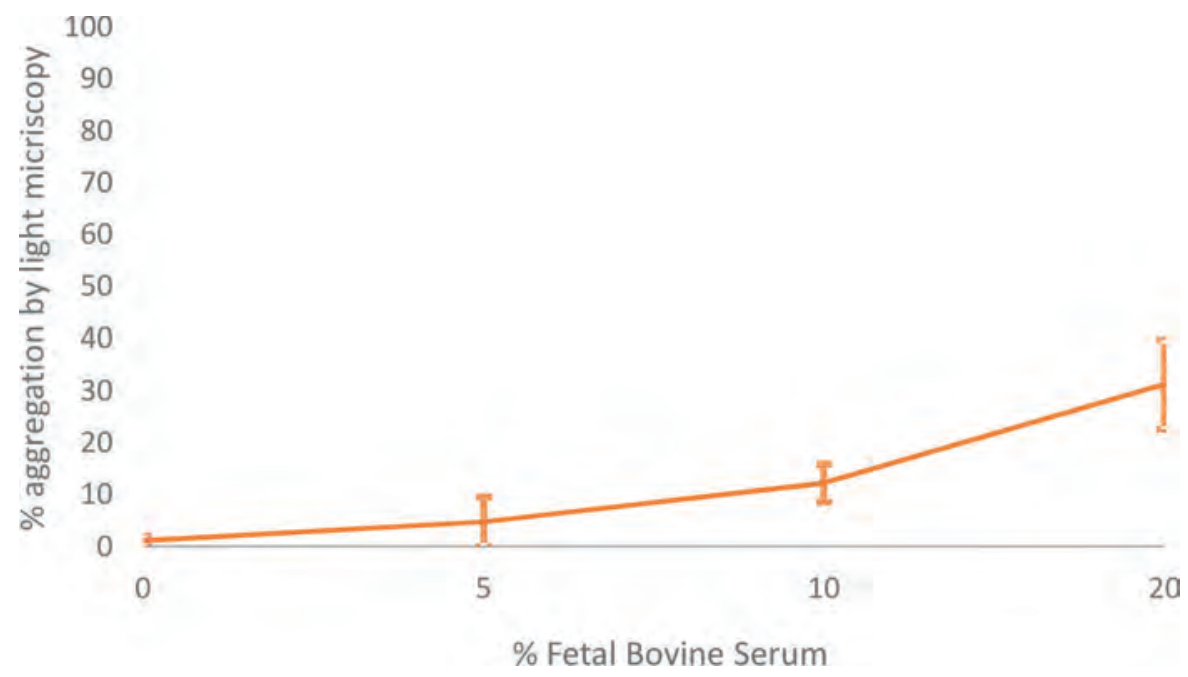

Figure 4 Graph showing percentage aggregation (as determined by light microscopy and Image J software) at various concentrations of FBS. Data presented as mean \pm 1 standard deviation of three independent experiments. 

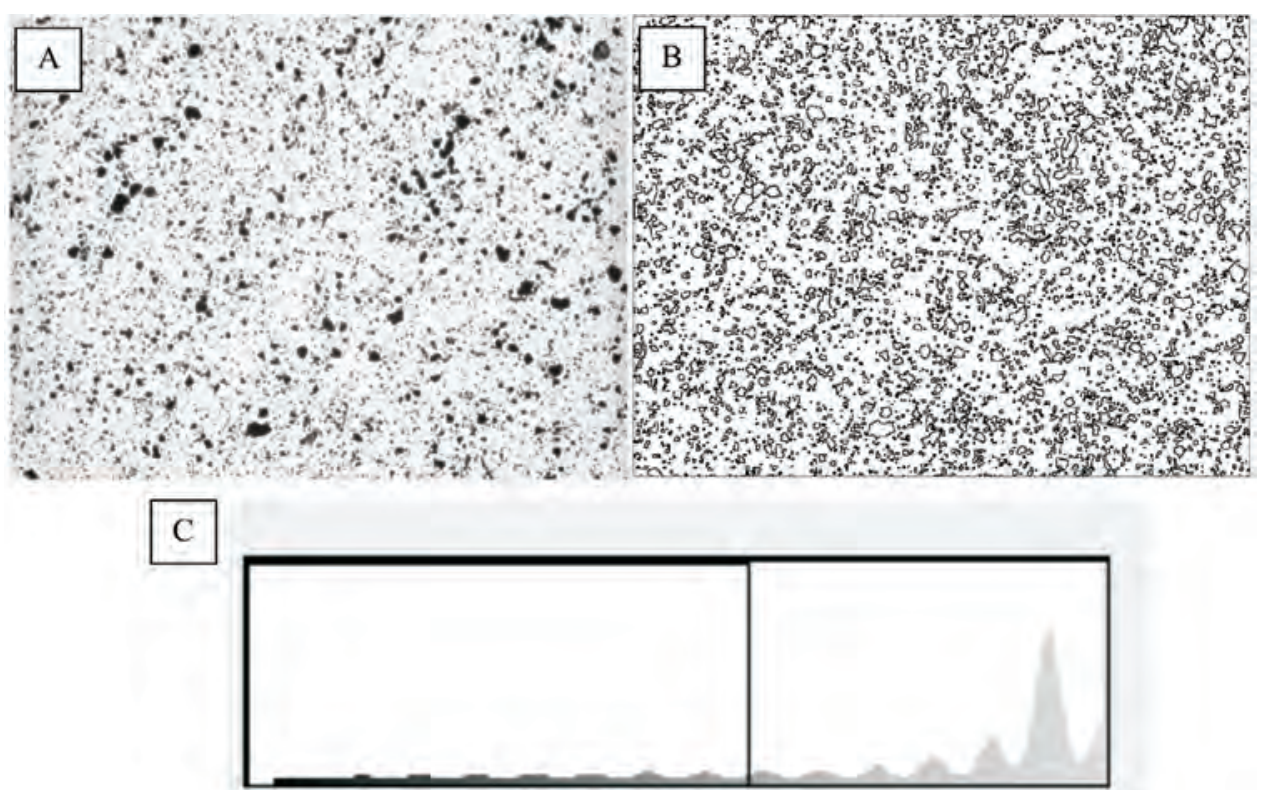

\section{$10.43 \%$}

Figure 5 Black and white (8-bit) image of aggregated gold nanoparticles under light microscopy (A) and the transformed image used by ImageJ (B) to estimate the 2-D surface area $(16.43 \%)$ of the aggregated nanoparticles (C).

added to the reaction was conjugated to the surface of the GNP. Therefore, the efficiency of RNA conjugation in our experiments is in keeping with that of Lee et al. ${ }^{15}$ Further details may be found in the section on RNA concentration in the Supplementary Material (Appendix F).

\subsection{Cell Uptake}

Fluorometric measurements revealed that approximately 43 polyethyleneimine-coated nanoparticles were taken up per cell (corresponding to $\sim 45000$ strands of RNA) (Table 2). This finding is consistent with electron microscopy enumeration of uptake ( $\sim 30$ nanoparticles per cell, for example, in Fig. 7C). It is difficult to compare these results to published data, for several reasons. Firstly, there are relatively few studies that quantify the number of gold nanoparticles taken up per cell. ${ }^{94}$ In most studies, uptake is gauged by methods such as flow cytometry, fluorescent microscopy or functional effects, which do not explicitly quantify the number of nanoparticles taken up per cell. Secondly, the uptake of nanoparticles by cells is influenced by various factors including nanoparticle concentration, clustering, size, shape and surface functionalization/capping and cell type, size $^{95}$ and orientation, ${ }^{96}$ and experimental factors including incubation period and temperature..$^{67,94,97-98}$ In particular, uptake appears to be significantly diminished in suspension cultures (as in this paper) as opposed to adherent monolayers. ${ }^{99}$ Thirdly, the method of enumeration may yield divergent results. ${ }^{96}$ It is therefore not surprising that estimates of nanoparticle uptake vary widely, from as low as 45 nanoparticles (nanorods) per cell ${ }^{100}$ (comparable to the findings of this paper), to hundreds ${ }^{101}$ or thousands of nanoparticles per cell. ${ }^{22,67,94,96,102}$

There was no significant uptake of free RNA and RNA bound to nanoparticles not coated with polyethyleneimine $(0$ and $<600$ strands per cell, respectively). Uptake of RNA was below the limit of detection by epifluorescent microscopy and flow cytometry (Fig. 6). A series of experiments were undertaken to improve uptake, without success. See Supplementary Material (Appendix F) for further details of these experiments.

The preceding discussion is based on the assumption that the RNA was efficiently and completely released from the nanoparticle surface. If this was not the case, then uptake may have been underestimated by fluorescent methods (due to quenching of the fluorescent signal by the gold nanoparticle). This may explain, at least partly, the negative results on flow cytometry and epifluorescent microscopy.

Light microscopy and electron microscopy showed significant aggregation of the nanoparticles in the extracellular medium

Table 2 Fluorometric measurement of uptake of RNA and nanoparticles by MT4 lymphocytes.

\begin{tabular}{lccc}
\hline Treatment & Increase in RFU ${ }^{1}$ post-lysis & $\begin{array}{c}\text { Estimated number of strands of } \\
\text { RNA taken up per cell }\end{array}$ & $\begin{array}{c}\text { Calculated number of } \\
\text { nanoparticles taken up per cell }\end{array}$ \\
\hline Buffer (negative control) & 0 & 0 & - \\
Free RNA & 1 & 0 & - \\
$\begin{array}{l}\text { Uncoated nanoparticle (nanoparticle } \\
\text { without polyethyleneimine coating) }\end{array}$ & 5 & $<600$ strands per cell $^{3}$ & $<1$ \\
$\begin{array}{l}\text { Complete nanoparticle (with } \\
\text { polyethyleneimine coating) }\end{array}$ & 93 & 45000 & 43
\end{tabular}

\footnotetext{
${ }^{1}$ Relative fluorescence units (RFU)

${ }^{2}$ Based on 1050 strands of RNA per nanoparticle and assuming $100 \%$ detachment of RNA from the surface of all nanoparticles.

${ }^{3}$ Limit of detection $=600$ strands per cell (corresponding to RFU $=5.3$ ).
} 


\section{DAPI nuclear stain (Blue)}

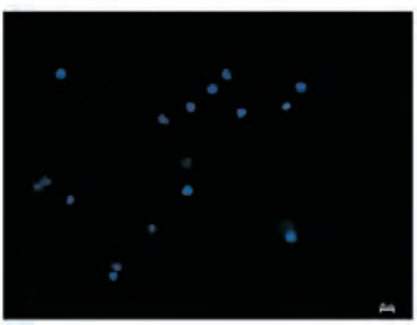

A Untreated

B

Treated

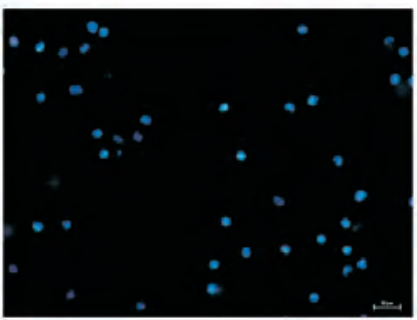

Fluorescein (Green)
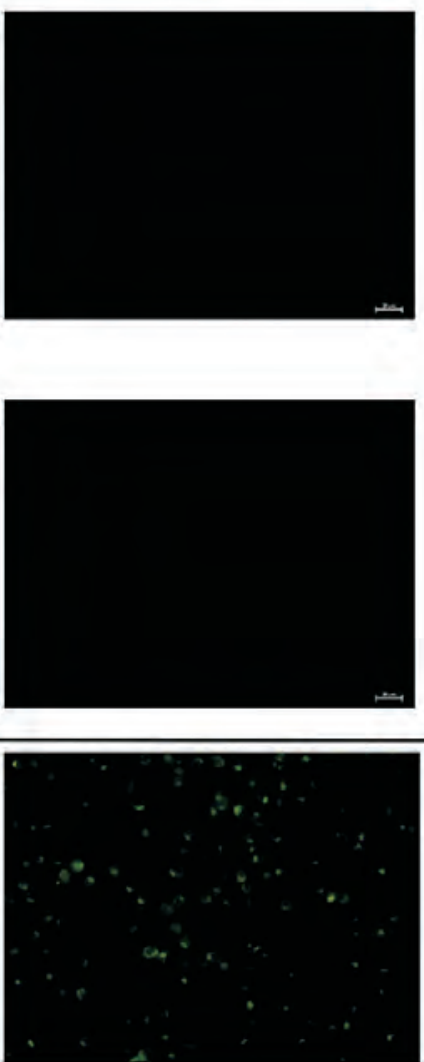

Flow Cytometry
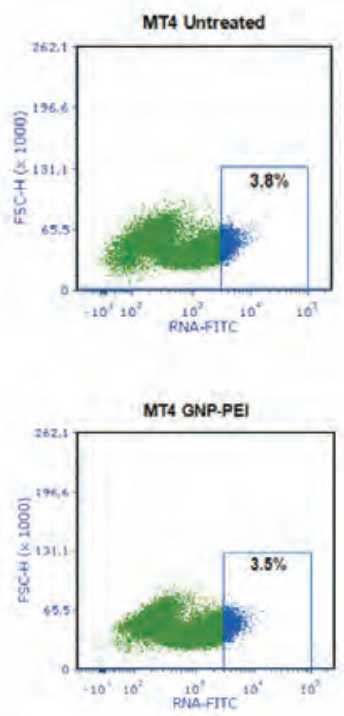

C

GNP-FITC
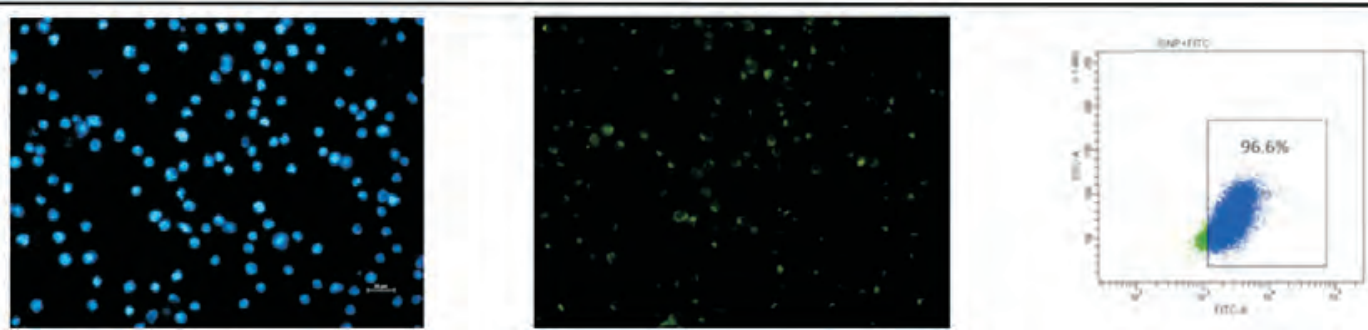

Figure 6 Epifluorescent microscopy (left) and flow cytometry results (right) showing untreated MT4 lymphocytes (A) and lymphocytes treated with polyethyleneimine-coated gold nanoparticles containing fluorescently tagged RNA $(\mathbf{B})$. The nuclei of cells stained with DAPI are clearly visible on epifluorescent microscopy (blue). Visualization using the fluorescein filter showed no obvious uptake of the polyethyleneimine-coated gold nanoparticle. The corresponding flow cytometry results show no difference between the untreated control (A) and cells treated with the polyethyleneimine-coated gold nanoparticles (B) (3.8vs. $3.5 \%$ ). By comparison, in an experiment with FITC labelled gold nanoparticles (C), there is obvious uptake (indicated by green fluorescence) and the corresponding flow cytometry results indicate that $96.6 \%$ of treated cells had positive fluorescence (shown in blue, in this case). (See Acknowledgements section.)
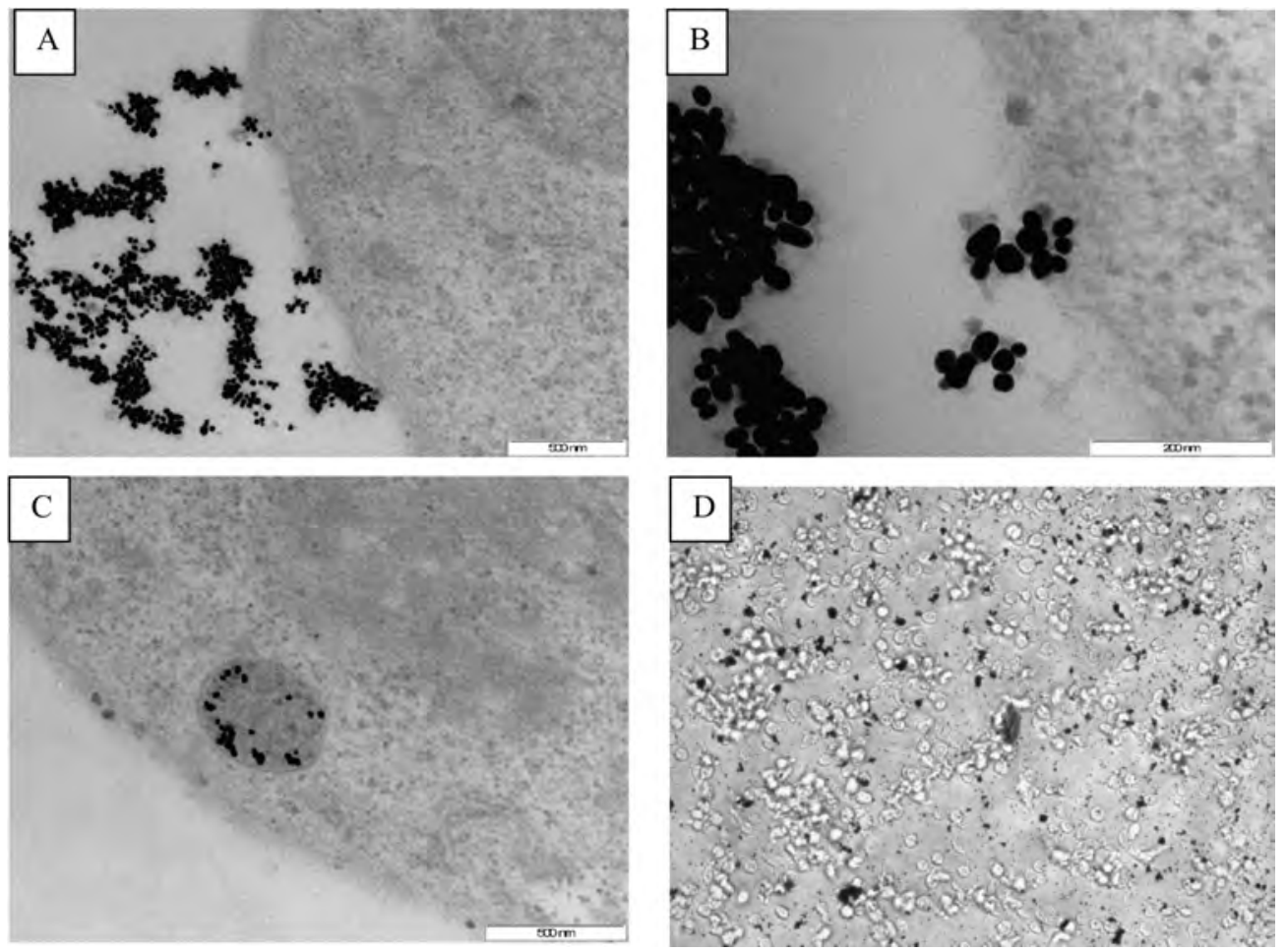

Figure 7 Electron micrograph of gold nanoparticles show extensive extracellular aggregation (A and B), while only occasional nanoparticles are found within a vesicle in the cytoplasm (C). The aggregates are visible on light microscopy as well (D). 
(Fig. 7). Another study using polyethyleneimine-coated gold nanoparticles for gene delivery has documented similar aggregation issues, which the authors attributed to the lyophilization and reconstitution process used in the preparation of the nanoparticle. ${ }^{103}$ This is not a consideration since lyophilization was not used in our study. Another study attributed the aggregation to polyethyleneimine reaching its saturation point in the reaction mixture, and suggested optimization of the loading density of the polyethyleneimine on the gold nanoparticle surface (determined to be 1000 molecules of polyethyleneimine per gold nanoparticle in their system). ${ }^{104}$ This limit was not exceeded in our study. Extracellular aggregation of the nanoparticle may have contributed significantly to the seemingly poor uptake by lymphocytes.

\subsection{Cytotoxicity and Antiviral Activity}

The nanoparticles did not display significant toxicity (Table 1) or antiviral activity (Fig. 8) which was expected, given the poor uptake.

\section{Conclusion}

In this paper, a multifunctional nanoparticle, designed to facilitate transfection of a single-stranded RNA into MT4 lymphocytes, was synthesized and characterized. The loading of the RNA per nanoparticle ( 1 strand per $\sim 4.8 \mathrm{~nm}^{2}$ of nanoparticle surface area) exceeded that of Lee et al..$^{15}$ (1 strand per $\sim 18 \mathrm{~nm}^{2}$ and note: the RNA used in their study was double-stranded). The multifunctional nanoparticle successfully transfected MT4 lymphocytes, although at low efficiency. Measurement of fluorescence after lysis of treated cells showed uptake of $\sim 45000$ strands of RNA (or 43 nanoparticles) per cell. This degree of uptake was below the limit of detection by flow cytometry and epifluorescent microscopy and was probably insufficient to exert a significant cytotoxic or antiviral effect. However, other reasons, such as quenching of fluorescent signal and lack of potency of RNA construct, may also explain the negative uptake and antiviral effect, respectively.

The limited uptake and antiviral effect was probably due to significant aggregation of the polyethyleneimine-coated nanoparticles in the cell culture medium. Similar aggregation issues with polyethyleneimine-coated nanoparticles have been encountered in previous studies. ${ }^{42,103}$ It has been shown that aggregation has an effect on uptake, and that such effects are dependent not only on the size of the aggregates, but also on cell type. ${ }^{105}$ Furthermore, aggregation may be associated with leeching of the polyethelenimine from the surface of nanoparticles, with subsequent loss of its protective effect and thus degradation of RNA by nucleases (although we did not confirm this experimentally). In our study, aggregation was quantified by photographic software and showed a dose response effect to

A

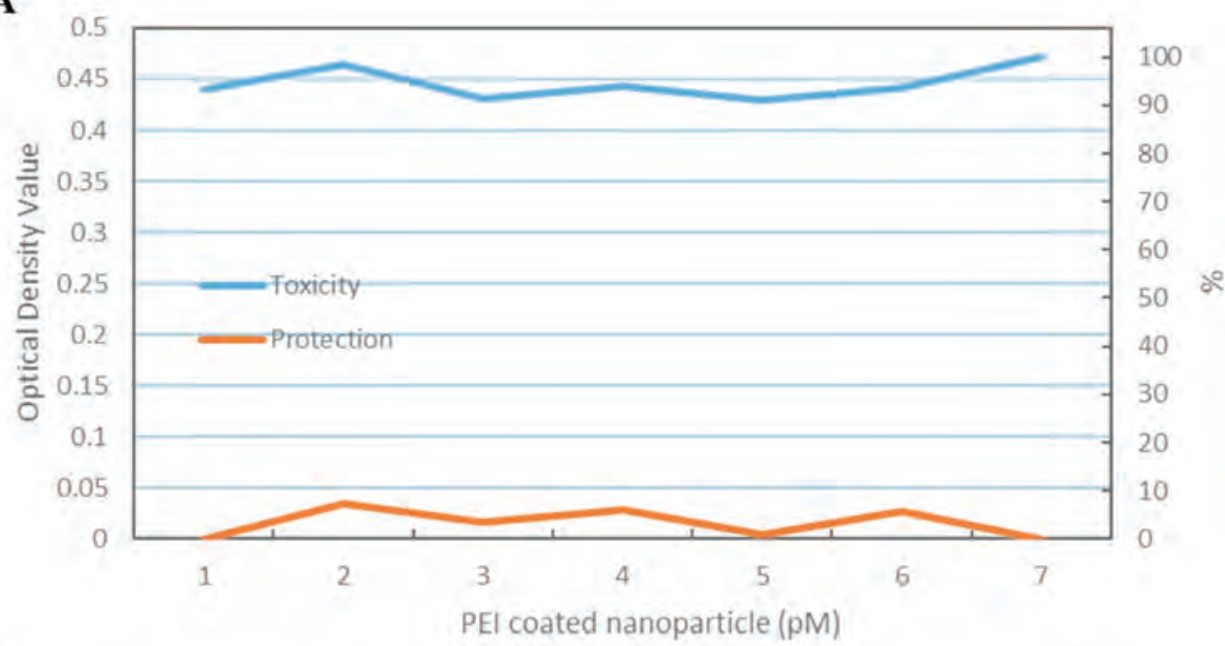

B

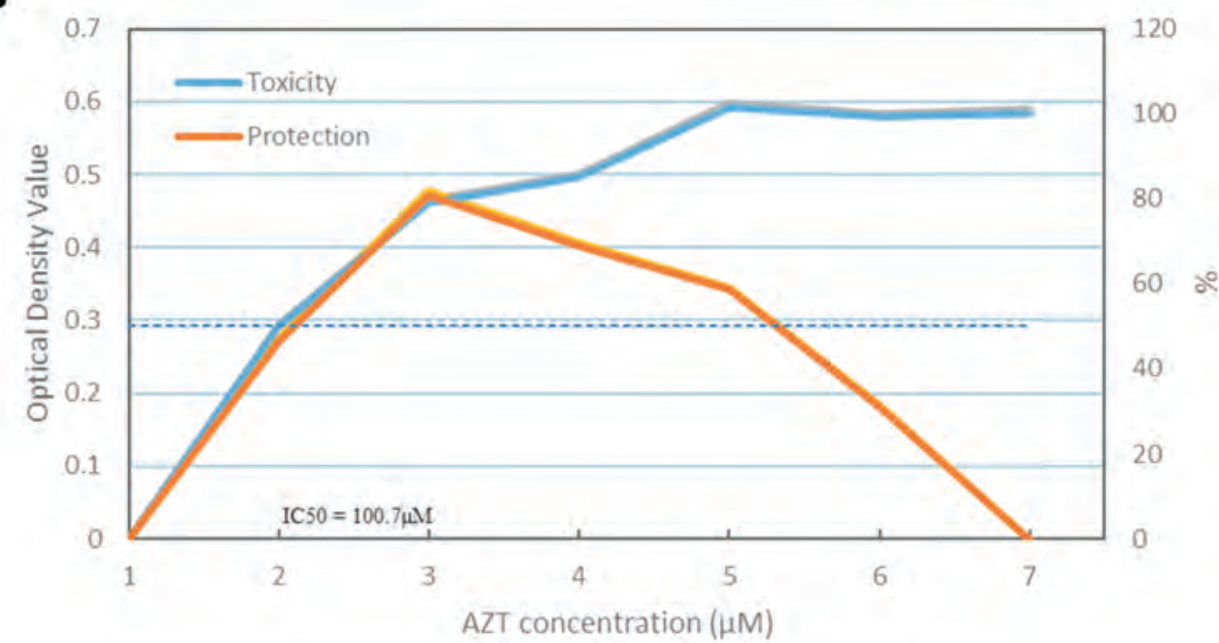

Figure 8 Graphical representation of results of the antiviral MTT assay. (A) Results for the polyethyleneimine-coated nanoparticle, which show no activity or cytotoxicity at the concentrations tested. The AZT control $(\mathbf{B})$ has potent antiviral activity $\left(\mathrm{EC}_{50}=0.05 \mu \mathrm{M}\right)$ and is toxic only at high concentrations $\left(\mathrm{IC}_{50}=100.7 \mu \mathrm{M}\right)$, with selectivity index $\left(\mathrm{IC}_{50} / \mathrm{EC}_{50}\right)=2014$. 
increasing concentration of FBS, which suggests that the aggregation is induced by serum factors, most likely proteins. Attachment of the cyclic peptide ligand to the surface of the polyethyleneimine-coated gold nanoparticle exacerbated the aggregation.

It must be noted that we did not study whether particles were taken up singly, in clusters or as aggregates, nor did we study their fate upon entry into the intracellular environment (particularly with regard to whether aggregation increased or decreased over time, and how quickly, if at all, they exited the cell). Furthermore, we did not study the effect of aggregation on the release of RNA from the surface of the nanoparticle. If RNA release was hampered due to aggregation, this may have had led to quenching of fluorescent signals and subsequent underestimation of uptake. These are aspects for further study, probably by the use of ex vivo, real-time imaging techniques. ${ }^{106}$

The conjugation of RNA to the gold nanoparticle surface via the SPDP linker molecule was relatively inefficient (peaking at 1 strand per $4.8 \mathrm{~nm}^{2}$ of nanoparticle surface area). This means that the RNA was conjugated to only $\sim 8 \%$ of SPDP binding sites available on the surface of the gold nanoparticle. Over $90 \%$ of the RNA fails to conjugate and remains in the supernatant post-reaction. Another group using a similar strategy to link RNA onto gold nanoparticles revealed a similar low efficiency (by our calculation, only $6 \%$ of available SPDP binding sites were conjugated to RNA). Increasing the input concentration of RNA did not lead to an increase in RNA loading per nanoparticle. This is a major limitation compared to transfection using dendrimers for example, where effectively all the RNA is complexed into the dendriplex. ${ }^{31}$

Furthermore, the inefficient binding of RNA to the surface of the gold nanoparticle may be a mechanistic factor that contributes to the aggregation of the nanoparticle. The low density of RNA (as evident by relatively high zeta potential values) implies that the surface of the gold nanoparticle may not have sufficient negative charge to retain the positively charged polyethyleneimine upon its surface (which may have led to partial leaching of the polyethyleneimine and aggregation - see Fig. S3 in Supplementary Material). The negative charge of gold nanoparticles at the RNA conjugation stage (prior to polyethyleneimine coating) in our experiments did not exceed $\sim 8 \mathrm{mV}$. By comparison, the zeta potential achieved in a layer-by-layer (non-covalent) approach by Elbakry et al. was at least double this value ( -20 to $-40 \mathrm{mV}){ }^{42}$ However, other factors, such as the size of the gold nanoparticle (either as single entities or clusters) and the length of polyethyleneimine are likely to play a role since the wrapping process is governed by the length of the polymer relative to surface curvature of the nanoparticle. ${ }^{42}$

The reasons for the low conjugation of RNA to the linker molecule may include steric hindrance or charge repulsion, which prevent high-density packing of covalently bound RNA molecules. By contrast, a layer-by-layer approach facilitates higher density RNA packing due to the presence of the positively charged polyethyleneimine in the underlying layer (which may counteract charge repulsion). Furthermore, the density and orientation of RNA packing in a layer-by-layer approach are not limited by the availability of linker molecules for covalent bond formation. Possibly, for these reasons, there were 780 siRNA strands per $15 \mathrm{~nm}$ nanoparticle (i.e. 1.1 RNA per $\mathrm{nm}^{2}$ ) in Elbakry's layer-by-layer approach, which is more than 5-fold greater loading than achieved by the approach in our paper.

Although the construct described in this paper had limited uptake and antiviral effect, details provided in terms of synthesis and characterization of the nanoparticle and quantification of aggregation may be useful for the assessments of nanoparticles with similar issues. Further studies are required to understand the factors that may explain and improve the loading of RNA onto the surface of gold nanoparticles using the approach adopted in this paper. In addition, it will be of interest to study whether aggregation may be prevented by increasing the loading of the RNA, or alternatively replicating this study with other cationic polymers (including low molecular weight and linear polyethyleneimine). Finally, it is not known whether this phenomenon is unique to single-stranded RNA and studies with double-stranded RNA and DNA may yield more favourable results.

\section{Acknowledgements}

The authors wish to thank Kogi Moodley and Prof. Daniels of UKZN for use of flow cytometry equipment and Lorika Beukes at the Microscopy \& Microanalysis Unit of UKZN for use of the confocal microscope and Phillip Christopher for assistance with electron microscopy and the DST-NRF Internship program for intern (William Serumula) to assist with laboratory maintenance and assistance. Dr Parboosing received an Academic Fellowship award from the Discovery Foundation of South Africa and funding from the National Research Foundation Thuthuka Program.

Dr Louis Chonco, under the supervision of Dr R. Parboosing, performed the experiments to provide a positive control and assisted with the images for Fig. 6.

\section{References}

1 L. Scherer, J.J. Rossi and M.S. Weinberg, Progress and prospects: RNA-based therapies for treatment of HIV infection. Gene Ther., 2007, 14(14), 1057-1064.

2 R. Kole, A.R. Krainer and S. Altman, RNA therapeutics: beyond RNA interference and antisense oligonucleotides. Nat. Rev. Drug Discov., 2012, 11(2), 125-140.

3 J.C. Burnett, J.A. Zaia and J.J. Rossi, Creating genetic resistance to HIV. Current Opinion in Immunology, 2012, 24(5), 625-632.

4 Y. Gao, X.L. Liu and X.R. Li, Research progress on siRNA delivery with nonviral carriers. Int. J. Nanomedicine, 2011, 6, 1017-1025.

5 S. Akhtar, M.D. Hughes, A. Khan, M. Bibby, M. Hussain, Q. Nawaz, J. Double and P. Sayyed, The delivery of antisense therapeutics. Advanced Drug Delivery Reviews, 2000, 44(1), 3-21.

6 S.S. Kim, H. Garg, A. Joshi and N. Manjunath, Strategies for targeted nonviral delivery of siRNAs in vivo. Trends in Molecular Medicine, 2009, 15(11), 491-500.

7 A. Aigner, Cellular Delivery in vivo of siRNA-based therapeutics. Current Pharmaceutical Design, 2008, 14(34), 3603-3619.

8 Y. Zhang, A. Satterlee and L. Huang, In vivo gene delivery by nonviral vectors: overcoming hurdles? Mol. Ther., 2012, 20(7), 1298-1304.

9 F.T. Vicentini, L.N. Borgheti-Cardoso, L.V. Depieri, D. de Macedo Mano, T.F. Abelha, R. Petrilli and M.V. Bentley, Delivery systems and local administration routes for therapeutic siRNA. Pharm. Res., 2013, 30(4), 915-931.

10 S. Akhtar and I.F. Benter, Nonviral delivery of synthetic siRNAs in vivo. J. Clin. Invest., 2007, 117(12), 3623-3632.

11 S. Ramishetti, R. Kedmi, M. Goldsmith, F. Leonard, A.G. Sprague, B. Godin, M. Gozin, P.R. Cullis, D.M. Dykxhoorn and D. Peer, Systemic gene silencing in primary T lymphocytes using targeted lipid nanoparticles. ACS Nano, 2015, 9(7), 6706-6716.

12 P. Kesharwani, V. Gajbhiye and N.K. Jain, A review of nanocarriers for the delivery of small interfering RNA. Biomaterials, 2012, 33(29), 7138-7150.

13 C. Scholz and E. Wagner, Therapeutic plasmid DNA versus siRNA delivery: common and different tasks for synthetic carriers. J. Control Release, 2012, 161(2), 554-565. 
14 K. Gao and L. Huang, Nonviral methods for siRNA delivery. Molecular Pharmaceutics, 2009, 6(3), 651-658.

15 J.S. Lee, J.J. Green, K.T. Love, J. Sunshine, R. Langer and D.G. Anderson, Gold, poly(beta-amino ester) nanoparticles for small interfering RNA delivery. Nano Lett., 2009, 9(6), 2402-2406.

16 K.K. Sandhu, C.M. McIntosh, J.M. Simard, S.W. Smith and V.M. Rotello, Gold nanoparticle-mediated transfection of mammalian cells. Bioconjugate Chem., 2002, 13(1), 3-6.

17 T. Niidome, K. Nakashima, H. Takahashi and Y. Niidome, Preparation of primary amine-modified gold nanoparticles and their transfection ability into cultivated cells. Chemical Communications, 2004, 2004(17), 1978-1979.

18 W.R. Glomm, Functionalized gold nanoparticles for applications in bionanotechnology. J. Disper. Sci. Technol., 2005, 26(3), 389-414.

19 Z.P. Xu, Q.H. Zeng, G.Q. Lu and A.B. Yu, Inorganic nanoparticles as carriers for efficient cellular delivery. Chem. Eng. Sci., 2006, 61(3), 1027-1040.

20 G. Han, P. Ghosh and V.M. Rotello, Functionalized gold nanoparticles for drug delivery. Nanomedicine (Lond.), 2007, 2(1), 113-123.

21 R. Sardar, A.M. Funston, P. Mulvaney and R.W. Murray, Gold nanoparticles: past, present, and future. Langmuir, 2009, 25(24), 13840-13851.

22 D.A Giljohann, D.S. Seferos, W.L. Daniel, M.D. Massich, P.C. Patel and C.A. Mirkin, Gold nanoparticles for biology and medicine. Angew Chem. Int. Edn. Engl., 2010, 49(19), 3280-3294.

23 B. Duncan, C. Kim and V.M. Rotello, Gold nanoparticle platforms as drug and biomacromolecule delivery systems. J. Control Release, 2010, 148(1), 122-127.

24 D. Pissuwan, T. Niidome and M.B. Cortie, The forthcoming applications of gold nanoparticles in drug and gene delivery systems. J. Control Release, 2011, 149(1), 65-71.

25 A.K. Lytton-Jean, R. Langer and D.G. Anderson, Five years of siRNA delivery: spotlight on gold nanoparticles. Small, 2011, 7(14): 1932-1937.

26 M. Thomas and A.M. Klibanov, Conjugation to gold nanoparticles enhances polyethylenimine's transfer of plasmid DNA into mammalian cells. Proc. Natl. Acad. Sci. USA, 2003, 100(16), 9138-9143.

27 P. Ghosh, Han, G., M. De, C.K. Kim and V.M. Rotello, Gold nanoparticles in delivery applications. Adv. Drug Deliv. Rev., 2008, 60(11), 1307-1315.

28 J.V. Jokerst, T. Lobovkina, R.N. Zare and S.S. Gambhir, Nanoparticle PEGylation for imaging and therapy. Nanomedicine (Lond,), 2011, 6(4), 715-28.

29 K. Rahme, L. Chen, R.G. Hobbs, M.A. Morris, C. O'Driscoll and J.D. Holmes, PEGylated gold nanoparticles: polymer quantification as a function of PEG lengths and nanoparticle dimensions. RSC Advances, 2013, 3(17), 6085

30 R. Hong, G. Han, J.M. Fernandez, B.J. Kim, N.S. Forbes and V.M., Rotello, Glutathione-mediated delivery and release using monolayer protected nanoparticle carriers. J. Am. Chem. Soc., 2006, 128(4), 1078-1079.

31 R. Parboosing, L. Chonco, FJ. de la Mata, T. Govender, G.E. Maguire and H.G. Kruger, Potential inhibition of HIV-1 encapsidation by oligoribonucleotide-dendrimer nanoparticle complexes. Int. J. Nanomedicine, 2016, 12, 317-325. .

32. Y. Lee, S.H. Lee, J.S. Kim, A. Maruyama, X. Chen and T.G. Park, Controlled synthesis of PEI-coated gold nanoparticles using reductive catechol chemistry for siRNA delivery. J. Control Release, 2011, 155(1), 3-10.

33 W.T. Godbey, M.A. Barry, P. Saggau, K.K. Wu and A.G. Mikos, Poly(ethylenimine)-mediated transfection: a new paradigm for gene delivery. J. Biomed. Mater. Res., 2000, 51(3), 321-328.

34 M.L. Forrest, J.T. Koerber and D.W. Pack, A degradable polyethylenimine derivative with low toxicity for highly efficient gene delivery. Bioconjug. Chem., 2003, 14(5), 934-940.

35 U. Lungwitz, M. Breunig, T. Blunk and A. Gopferich, Polyethylenimine-based non-viral gene delivery systems. Eur. J. Pharm. Biopharm., 2005, 60(2), 247-266.

36 A.C. Grayson, A.M. Doody and D. Putnam, Biophysical and structural characterization of polyethylenimine-mediated siRNA delivery in vitro. Pharm. Res., 2006, 23(8), 1868-1876.
37 S. Werth, B. Urban-Klein, L. Dai, S. Hobel, M. Grzelinski, U. Bakowsky, F. Czubayko and A. Aigner, A low molecular weight fraction of polyethylenimine (PEI) displays increased transfection efficiency of DNA and siRNA in fresh or lyophilized complexes. J. Control Release, 2006, 112(2), 257-270.

38 S. Kawakami and M. Hashida, Targeted delivery systems of small interfering RNA by systemic administration. Drug Metab. Pharmacokinet., 2007, 22(3), 142-151.

39 S. Boe, A.S. Longva and E. Hovig, Evaluation of various polyethylenimine formulations for light-controlled gene silencing using small interfering RNA molecules. Oligonucleotides, 2008, 18(2), 123-132.

40 Y.M. Park, B.A. Shin and I.J. Oh, Poly(L-lactic acid)/polyethylenimine nanoparticles as plasmid DNA carriers. Arch. Pharm. Res., 2008, 31(1), 96-102.

41 H. Katas, E. Cevher and H.O. Alpar, Preparation of polyethyleneimine incorporated poly(D,L-lactide-co-glycolide) nanoparticles by spontaneous emulsion diffusion method for small interfering RNA delivery. Int. J. Pharm., 2009, 369(1-2), 144-154.

42 A. Elbakry, A. Zaky, R. Liebl, R. Rachel, A. Goepferich and M. Breunig, Layer-by-layer assembled gold nanoparticles for siRNA delivery. Nano Lett, 2009, 9(5), 2059-2064.

43 W.J. Kim and S.W. Kim, Efficient siRNA delivery with non-viral polymeric vehicles. Pharm. Res., 2009, 26(3), 657-666.

44 S. Hobel, I. Koburger, M. John, F. Czubayko, P. Hadwiger, H.P. Vornlocher and A. Aigner, Polyethylenimine/small interfering RNA-mediated knockdown of vascular endothelial growth factor in vivo exerts anti-tumor effects synergistically with Bevacizumab. J. Gene Med., 2010, 12(3), 287-300.

45 K. Itaka, A. Harada, Y., Yamasaki, K. Nakamura, H. Kawaguchi and K. Kataoka, In situ single cell observation by fluorescence resonance energy transfer reveals fast intra cytoplasmic delivery and easy release of plasmid DNA complexed with linear polyethylenimine. J. Gene Medicine, 2004, 6(1), 76-84.

46 S. Guo, Y. Huang, Q., Jiang, Y. Sun, L. Deng, Z. Liang, Q. Du, J. Xing, Y. Zhao, P.C. Wang, A. Dong and X.J. Liang, Enhanced gene delivery and siRNA silencing by gold nanoparticles coated with chargereversal polyelectrolyte. ACS Nano, 2010, 4(9), 5505-5511.

47 W.J. Song, J.Z. Du, T.M., Sun, P.Z. Zhang and J. Wang, Gold nanoparticles capped with polyethyleneimine for enhanced siRNA delivery. Small, 2010, 6(2), 239-246.

48 A. Sharma, A. Tandon, J.C. Tovey, R. Gupta, J.D. Robertson, J.A. Fortune, A.M. Klibanov, J.W. Cowden, F.G. Rieger and R.R. Mohan, Polyethylenimine-conjugated gold nanoparticles: gene transfer potential and low toxicity in the cornea. Nanomedicine, 2011, 7(4), 505-513.

49 M. Mitra, M. Kandalam, J. Rangasamy, B. Shankar, U.K. Maheswari, S. Swaminathan and S. Krishnakumar, Novel epithelial cell adhesion molecule antibody conjugated polyethyleneimine-capped gold nanoparticles for enhanced and targeted small interfering RNA delivery to retinoblastoma cells. Molecular Vision, 2013, 19, 1029-1038.

50 Y. Ding, Z. Jiang, K. Saha, C.S. Kim, S.T. Kim, R.F. Landis and V.M. Rotello, Gold nanoparticles for nucleic acid delivery. Mol. Ther., 2014, 22(6), 1075-1083.

51 R., Kircheis, A. Kichler, G., Wallner, M. Kursa, M. Ogris, T. Felzmann, $\mathrm{M}$. Buchberger and E. Wagner, Coupling of cell-binding ligands to polyethylenimine for targeted gene delivery. Gene Ther., 1997, 4(5), 409-418.

52 T. Blessing, M. Kursa, R., Holzhauser, R. Kircheis and E. Wagner, Different strategies for formation of PEGylated EGF-conjugated PEI/DNA complexes for targeted gene delivery. Bioconjug. Chem., 2001, 12(4), 529-537.

53 E. Kleemann, M. Neu, N. Jekel, L. Fink, T. Schmehl, T. Gessler, W. Seeger and T. Kissel, Nano-carriers for DNA delivery to the lung based upon a TAT-derived peptide covalently coupled to PEG-PEI. J. Control Release, 2005, 109(1-3), 299-316.

54 M. Lee, J.S. Choi, M.J. Choi, Y.K. Pak, B.D. Rhee and K.S. Ko, DNA delivery to the mitochondria sites using mitochondrial leader peptide conjugated polyethylenimine. J. Drug Target., 2007, 15(2), 115-122.

$55 \mathrm{~J}$. Zeng, X. Wang and S. Wang, Self-assembled ternary complexes of plasmid DNA, low molecular weight polyethylenimine and target- 
ing peptide for nonviral gene delivery into neurons. Biomaterials, 2007, 28(7), 1443-1451.

56 C. Strehblow, M. Schuster, T. Moritz, H.C. Kirch, B. Opalka and J.B. Petri, Monoclonal antibody-polyethyleneimine conjugates targeting Her-2/neu or CD90 allow cell type-specific nonviral gene delivery. J. Control Release, 2005, 102(3), 737-747.

57 C. Monnet, D., Laune, J. Laroche-Traineau, M. Biard-Piechaczyk, L. Briant, C. Bes, M. Pugniere, J.C. Mani, B. Pau, M. Cerutti, G. Devauchelle, C. Devaux, C. Granier and T. Chardes, Synthetic peptides derived from the variable regions of an anti-CD4 monoclonal antibody bind to CD4 and inhibit HIV-1 promoter activation in virusinfected cells. J. Biol. Chem., 1999, 274(6), 3789-3796.

58 C. Bes, L. Briant-Longuet, M. Cerruti, P. De Berardinis, G. Devauchelle, C. Devaux, C. Granier and T. Chardes, Efficient CD4 binding and immunosuppressive properties of the $13 \mathrm{~B} 8.2$ monoclonal antibody are displayed by its CDR-H1-derived peptide CB1 FEBS Lett., 2001, 508(1), 67-74.

59 C. Bes, L. Briant-Longuet, M. Cerutti, F. Heitz, S. Troadec, M. Pugniere, F. Roquet, F. Molina, F. Casset, D. Bresson, S. Peraldi-Roux, G. Devauchelle, C. Devaux, C. Granier and T. Chardes, Mapping the paratope of anti-CD4 recombinant Fab 13B8.2 by combining parallel peptide synthesis and site-directed mutagenesis. J. Biol. Chem., 2003, 278(16), 14265-14273.

60 F. Albericio, Developments in peptide and amide synthesis. Curr. Opin. Chem. Biol., 2004, 8(3), 211-221.

61 C.B. Boschek, D.O. Apiyo, T.A.Soares, H.E. Engelmann, N.B. Pefaur, T.P. Straatsma and C.L. Baird, Engineering an ultra-stable affinity reagent based on Top7. Protein Eng. Des. Sel., 2009, 22(5), 325-332.

62 M. Popovic, E. Read-Connole and R.C. Gallo, T4 positive human neoplastic cell lines susceptible to and permissive for HTLV-III. Lancet, 1984, 2(8417-8418), 1472-1473.

63 M. Popovic, M.G. Sarngadharan, E. Read and R.C. Gallo, Detection, isolation, and continuous production of cytopathic retroviruses (HTLV-III) from patients with AIDS and pre-AIDS. Science, 1984, 224(4648), 497-500.

64. L. Ratner, W. Haseltine, R. Patarca, K.J. Livak, B. Starcich, S.F. Josephs, E.R. Doran, J.A. Rafalski, E.A. Whitehorn, K. Baumeister, et al., Complete nucleotide sequence of the AIDS virus, HTLV-III. Nature, 1985, 313(6000), 277-284.

65 J. Turkevich, Colloidal gold. Part II. Gold Bulletin, 1985, 18(4), 125-131.

66 M.C. Daniel and D. Astruc, Gold nanoparticles: assembly, supramolecular chemistry, quantum-size-related properties, and applications toward biology, catalysis, and nanotechnology. Chem. Rev., 2004, 104(1), 293-346.

67 B.D. Chithrani, A.A. Ghazani and W.C. Chan, Determining the size and shape dependence of gold nanoparticle uptake into mammalian cells. Nano Lett., 2006, 6(4), 662-668.

68 A.G. Kanaras, Z. Wang, I. Hussain, M. Brust, R. Cosstick and A.D. Bates, Site-specific ligation of DNA-modified gold nanoparticles activated by the restriction enzyme StyI. Small, 2007, 3(1), 67-70.

69 W. Haiss, N.T.K. Thanh, J. Aveyard and D.G. Fernig, Determination of size and concentration of gold nanoparticles from UV-vis spectra. Analytical Chemistry, 2007, 79(11), 4215-4221.

70 G. Zhang, Z. Yang, W. Lu, R. Zhang, Q. Huang, M. Tian, L. Li, D. Liang and $\mathrm{C}$. Li, Influence of anchoring ligands and particle size on the colloidal stability and in vivo biodistribution of polyethylene glycolcoated gold nanoparticles in tumor-xenografted mice. Biomaterials, 2009, 30(10), 1928-1936.

71. Thermoscientific TCEP Reaction for Thiol-Modified siRNA/RNA Oligonucleotides. www.thermoscientific.fr/eThermo/CMA/PDFs/ Various/File_7282.pdf (accessed on 24 August, 2016).

72 ThermoScientific Thermo Scientific Deprotection 2'-ACE Protected RNA. http://dharmacon.gelifesciences.com/uploadedFiles/Products/Custom_Synthesis/Single-stranded_RNA_Synthesis/deprotection-protocol.pdf (accessed on 24 August 2016).

73 D.A. Giljohann, D.S. Seferos, A.E. Prigodich, P.C. Patel and C.A. Mirkin, Gene regulation with polyvalent siRNA-nanoparticle conjugates. J Am Chem Soc, 2009, 131(6), 2072-2073.

74 D.A. Wellings and E. Atherton, Standard Fmoc protocols. Methods Enzymol, 1997, 289, 44-67.
75 G. Fields, Solid-phase peptide synthesis. Molecular Biomethods Handbook, 1998, 527-545.

76 M. Amblard, J.A. Fehrentz, J. Martinez and G. Subra, Methods and Protocols of modern solid phase peptide synthesis. Mol. Biotechnol., 2006, 33(3), 239-254.

77 R. Rapley and J.M. Walker, Molecular Biomethods Handbook, 2nd edn., Humana Press, Totowa, NJ, 2008, p. 515.

78 N. Sewald and H.-D. Jakubke, Peptide Synthesis. Wiley-VCH Verlag GmbH \& Co. KGaA: 2009, pp. 175-315.

79 K. Muthusamy, F. Albericio, P.I. Arvidsson, P. Govender, H.G. Kruger, G.E. Maguire and T. Govender, Microwave assisted SPPS of amylin and its toxicity of the pure product to RIN-5F cells. Biopolymers, 2010, 94(3), 323-330.

80 L.K. Pietersen, P. Govender, H.G. Kruger, G.E.M. Maguire, J. WesleySmith and T. Govender, Peptide functionalised gold nanoparticles: effect of loading on aggregation and proteolysis. International Journal of Peptide Research and Therapeutics, 2010, 16(4), 291-295.

81 A.S. Galanis, F. Albericio and M. Grotli, Enhanced microwaveassisted method for on-bead disulfide bond formation: synthesis of alpha-conotoxin MII. Biopolymers, 2009, 92(1), 23-34.

82 F. Chen, G.-Q. Xu and T.S.A. Hor, Preparation and assembly of colloidal gold nanoparticles in CTAB-stabilized reverse microemulsion. Materials Letters, 2003, 57(21), 3282-3286.

83 Image J Particle Analysis. http://www.webcitation.org/6ki40WIqj (accessed 22 September 2016).

84 W. Rasband, Image J, National Institutes of Health, 2016.

85 Thermoscientific SPDP Crosslinkers http://www.webcitation.org/ 6kgk4z9ud (accessed 18 January 2018).

86 Promega A GloMax-Multi Microplate Fluorometer Method for Fluorescein Measurement (Application Note). https://www.promega. com/-/media/files/resources/application-notes/glomax-multi-mmr/ a-glomax-multi-microplate-fluorometer-method-for-fluoresceinmeasurement.pdf?la=en (accessed 18 January 2018).

87 Bio-Imaging of Oxford University Sir William Dunn School of Pathology Standard fixation and embedding protocol for resin section TEM http://web.path.ox.ac.uk/ bioimaging/bitm/instructions_and_infor mation/EM/fixation_standard.pdf (accessed on 24 August 2016).

88 N. Weber, P. Ortega, M.I. Clemente, D. Shcharbin, M. Bryszewska, FJ. de la Mata, R. Gomez, and M.A. Munoz-Fernandez, Characterization of carbosilane dendrimers as effective carriers of siRNA to HIVinfected lymphocytes. J. Control Release, 2008, 132(1), 55-64.

89 T. Gonzalo, M. Clemente, L. Chonco, N. Weber, L. Diaz, M. Serramia, R. Gras, P. Ortega, F. de la Mata, R. Gomez, L. Lopez-Fernandez, M. Munoz-Fernandez and J. Jimenez, Gene therapy in HIV-infected cells to decrease viral impact by using an alternative delivery method. ChemMedChem., 2010, 5(6), 921-929.

90 C. Pannecouque, D. Daelemans and E. De Clercq, Tetrazolium-based colorimetric assay for the detection of HIV replication inhibitors: revisited 20 years later. Nature Protocols, 2008, 3(3), 427-434.

91 R. Parboosing, G. Mzobe, L. Chonco and I. Moodley, Cell-based assays for assessing toxicity: a basic guide. Medicinal Chemistry, 2016, Epub Ahead of Print ( Feb 29).

92 World Health Organization Laboratory Biosafety Manual. http://www.who.int/csr/resources/publications/biosafety/WHO CDS_CSR_LYO_2004_11/en/ (accessed on 24 August 2016).

93 Centers for Disease Control Biosafety in Microbiological and Biomedical Laboratories (BMBL) http://www.cdc.gov/biosafety/publications/bmbl5/ (accessed on 24 August 2016).

94 A.M. Alkilany and C.J. Murphy, Toxicity and cellular uptake of gold nanoparticles: what we have learned so far? J. Nanopart. Res., 2010, 12(7), 2313-2333.

95 X. Wang, X. Hu, J. Li, A.C. Russe, N. Kawazoe, Y. Yang and G. Chen, Influence of cell size on cellular uptake of gold nanoparticles. Biomaterials Science, 2016, 4(6), 970-978.

96 E.C. Cho, Q. Zhang and Y. Xia, The effect of sedimentation and diffusion on cellular uptake of gold nanoparticles. Nature Nanotechnology, 2011, 6(6), 385-391.

97 O. Betzer, R. Meir, T. Dreifuss, K.Shamalov, M.Motiei, A. Shwartz, K. Baranes, C.J. Cohen, N. Shraga-Heled, R. Ofir, G. Yadid and R.Popovtzer, In-vitro optimization of nanoparticle-cell labeling pro- 
tocols for in-vivo cell tracking applications. Scientific Reports, 2015, 5, 15400.

98 R. Lévy, U. Shaheen, Y. Cesbron and V. Sée, Gold nanoparticles delivery in mammalian live cells: a critical review. Nano Reviews, 2010,1(0).

99 A.C. Sabuncu, J.Grubbs, S. Qian, T.M. Abdel-Fattah, M.W. Stacey and A. Beskok, Probing nanoparticle interactions in cell culture media. Colloids Surf. B Biointerfaces, 2012, 95, 96-102.

100 A.M. Alkilany, P.K. Nagaria, C.R. Hexel, T.J. Shaw, C.J. Murphy and M.D. Wyatt, Cellular uptake and cytotoxicity of gold nanorods: molecular origin of cytotoxicity and surface effects. Small, 2009, 5(6), 701-708.

101 B.D. Chithrani and W.C. Chan, Elucidating the mechanism of cellular uptake and removal of protein-coated gold nanoparticles of different sizes and shapes. Nano Lett., 2007, 7(6), 1542-1550.

102 B. Rothen-Rutishauser, D.A. Kuhn, Z. Ali, M. Gasser, F. Amin, W.J. Parak, D. Vanhecke, A. Fink, P. Gehr and C. Brandenberger, Quanti- fication of gold nanoparticle cell uptake under controlled biological conditions and adequate resolution. Nanomedicine, 2014, 9(5), 607-621.

103 T. Ariyawansa, H. Pullman, M.M. Amiji and M.M.D Bhavsar,. The Development of Multifunctional Nanoparticles for Simultaneous Fluorescence Imaging and Gene Delivery. http://web.mit.edu/rsi/ www/pdfs/papers/2006/2006-thilini.pdf.

104 A.J. Nosser, The Characterization of AuNP-PEI Conjugates for siRNA Delivery to Cancer Cells, Honors thesis, The University of Southern Mississippi, Hattiesburg, Mississippi, USA, 2013. Available at: http:// aquila.usm.edu/honors_theses/179/ (accessed 18 January 2018).

105 A. Albanese and W.C. Chan, Effect of gold nanoparticle aggregation on cell uptake and toxicity. ACS Nano, 2011, 5(7), 5478-5489.

106 C.A. Cunha-Matos, O.R. Millington, A.W. Wark and M. Zagnoni, Real-time assessment of nanoparticle-mediated antigen delivery and cell response. Lab Chip, 2016, 16(17), 3374-3381 


\section{Supplementary material to:}

R. Parboosing, T. Govender, G.E.M. Maguire and H.G. Kruger,

Synthesis, Characterization and Biocompatibility of a Multifunctional Gold Nanoparticle System for the Delivery of Single-Stranded RNA to Lymphocytes,

S. Afr. J. Chem., 2018, 71, 1-14. 


\section{Supplementary Material}

\section{Appendix A: Confirming PEGylationby Gel Electrophoresis and Colloidal Stability Test}

PEGylation of the multifunctional nanoparticle is essential to ensure its stability in physiological solutions. ${ }^{1}$ Successful PEGylation was conveniently determined by the Colloidal Stability Test, in which the colour of a solution of bare (non-PEGylated) gold nanoparticles rapidly changes from wine red/pink to purple in the presence of high salt concentrations (indicating the formation of aggregates). PEGylated nanoparticles are stable in solutions containing high concentration of salts, and do not undergo any visible colour change (Figure S1).

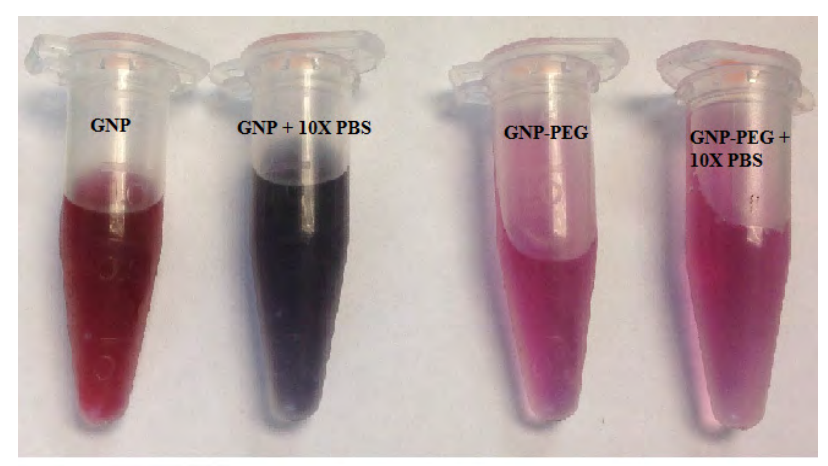

Figure S1: Colloidal Stability Test: A $1 \mathrm{ml}$ solution of bare gold nanoparticles (GNP), rapidly changes to a purple colour upon the addition of $100 \mu \mathrm{L} 10 x$ PBS (GNP + 10x PBS), while PEGylated gold nanoparticles (GNP-PEG) do not (GNP-PEG + 10x PBS).

Successful PEGylation may also be confirmed visually on gel electrophoresis since bare citrate capped gold nanoparticles are negatively charged ${ }^{2}$ while PEGylated gold nanoparticles are neutral (Figure S2). A $2 \%$ agarose gel was prepared with TBE (Tris/Borate/EDTA) buffer $(\mathrm{pH}=8.3)$. A $10 \mu \mathrm{L}$ aliquot of nanoparticle solution was mixed with an equal volume of $40 \% \mathrm{w} / \mathrm{v}$ sucrose and then loaded into the well of the agarose gel. The gel was run for 40 minutes at $120 \mathrm{~V}$. A sufficiently high concentration of gold nanoparticle solution was used to permit visualisation and photography of the "bands" on the gel.

Gel electrophoresis was also performed to confirm conjugation of RNA to gold nanoparticles i.e. to show that the fluorescent bands (RNA) co-localised with visible gold nanoparticle bands. However, fluorescence was not observed, probably due to the low number of RNA molecules per gold nanoparticle and surface quenching of the fluorescence signal. 


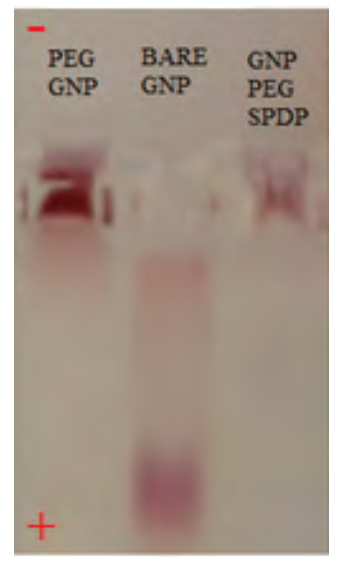

Figure S2: Gel electrophoresis of gold nanoparticles showing migration of negatively charged bare gold nanoparticles towards the positive pole. PEGylated gold nanoparticles (left lane) and PEGylated gold nanoparticles with SPDP linker molecule (right lane) have a neutral charge and do not migrate. 


\section{Appendix B: Peptide Synthesis ${ }^{3}$}

Design of the Peptide Ligand: Targeting CD4 Cells

A synthetic peptide, that specifically binds the CD4 receptor, was attached to the gold nanoparticle to potentially enhance receptor-mediated endocytosis and uptake of the nanoparticle by CD4+ MT4 lymphocytes. The design of the peptide was based on systematic exploration of the variable domains of an anti-CD4 mAb by the "Spot" method. ${ }^{4-8}$ This peptide has been shown to cause dose dependent inhibition of IL2 secretion by CD4+ cells, inhibition of HIV-1 promoter activation, specific, dosedependent binding to soluble CD4 in an ELISA assay and dose-dependent inhibition of binding to soluble CD4 by anti-CD4 mAb in an ELISA inhibition assay. ${ }^{5}$ An AAC "tail" links the peptide to the polyethyleneimine via an SPDP linker molecule. The peptide was synthesized by routine FMoc Solid Phase Synthesis ${ }^{3,9-12}$ on a CEM microwave peptide synthesizer ${ }^{13-14}$ and cyclised by on-resin iodineoxidation of cysteine residues close to the $\mathrm{N}$ and $\mathrm{C}$ termini of the peptide. ${ }^{7,15}$

\section{Reagents}

9-fluorenylmethoxycarbonyl (FMoc) protected amino acids and coupling reagents were purchased from GLS Biochem Systems. Solvents were purchased from Sigma-Aldrich.

\section{Peptide Sequence}

The sequence of the peptide is as follows:KC*LTTFGVHWVRQSC*KAAC ${ }^{\#}$. The peptide consists of 10 ( 53\%) hydrophobic, 4 ( 21\%) polar, 4 positively charged and 0 negatively charged amino acids. ${ }^{16}$ The "inner" cysteines that are involved in the cyclization reaction, are shown as $\mathrm{C}^{*}$, and the "tail" cysteine that links to the gold nanoparticle surface is shown as $C^{\#}$.

\section{Solid PhasePeptide synthesis}

FMoc Solid Phase Peptide synthesis was carried out in a C to N direction on a CEM microwave peptide synthesizer at a $0.1 \mathrm{mmol}$ scale. Rink amide resin was used as the solid support system. ${ }^{13-}$ ${ }^{14}$ Deprotection was achieved by $20 \%$

piperidine/DMF(dimethylformamide)(v/v) $)^{13}, 17$ and coupling by 1:1:1 amino acid/HBTU(N-[1Hbenzotriazol-1-yl)(dimethylamino)methylene]-N-methyl-methanaminium hexafluorophosphate $\mathrm{N}$-oxide)/ DIPEA (N,N-diisopropyl ethylamine) in DMF. ${ }^{13}$ Table S1 provides the details of side chain protection/deprotection strategy, while Table S2 lists the microwave synthesis conditions. DMF washes were performed between the deprotection and coupling steps. 
Table S1: Side Chain Protection/Deprotection ${ }^{3,11}$

\begin{tabular}{|c|c|c|c|c|c|}
\hline $\begin{array}{l}\# \\
\text { (L-R) }\end{array}$ & Amino Acid & $\begin{array}{l}\text { Letter } \\
\text { (label) }\end{array}$ & Symbol & Protection & Deprotection \\
\hline 1 & Lysine & $\mathbf{K}$ & Lys & $\mathrm{Mtt}$ & 95\%TFA \\
\hline 2 & Cysteine & $\mathrm{C}^{*}$ & Cys & Mmt & $1 \%$ TFA \\
\hline 3 & Leucine & $\mathbf{L}$ & leu & NONE & NONE \\
\hline 4 & Threonine & $\mathbf{T}$ & Thr & $\mathrm{tBu}$ & 95\%TFA \\
\hline 5 & Threonine & $\mathbf{T}$ & Thr & $\mathrm{tBu}$ & 95\%TFA \\
\hline 6 & Phenylalanine & $\mathbf{F}$ & Phe & NONE & NONE \\
\hline 7 & Glycine & G & Gly & NONE & NONE \\
\hline 8 & Valine & $\mathbf{V}$ & Val & NONE & NONE \\
\hline 9 & Histidine & $\mathbf{H}$ & His & Trt & 95\%TFA \\
\hline 10 & Tryptophan & $\mathbf{W}$ & Trp & Boc & 95\%TFA \\
\hline 11 & Valine & $\mathbf{V}$ & Val & NONE & NONE \\
\hline 12 & Arginine & $\mathbf{R}$ & Arg & Pbf & 95\% TFA \\
\hline 13 & Glutamine & $\mathbf{Q}$ & Gln & Trt & 95\% TFA \\
\hline 14 & Serine & $\mathbf{S}$ & Ser & $\mathrm{tBu}$ & 95\%TFA \\
\hline 15 & Cysteine & $\mathbf{C}^{*}$ & Cys & $\mathrm{Mmt}$ & $1 \%$ TFA \\
\hline 16 & Lysine & $\mathbf{K}$ & Lys & Boc & 95\%TFA \\
\hline 17 & Alanine & A & Ala & NONE & NONE \\
\hline 18 & Alanine & A & Ala & NONE & NONE \\
\hline 19 & Cysteine & $\mathbf{C}^{\#}$ & Cys & Trt & $95 \%$ TFA \\
\hline
\end{tabular}

Boc tert-butoxycarbonyl, Mmt 4-methoxytrityl, Pbf 2,2,4,6,7-pentamethyldihydrobenzofuran-5-sulfonyl,

Pmc 2,2,5,7,8-pentamethylchroman-6-sulfonyl, tBu tert-butyl, TFA trifluoroacetic acid, Trt

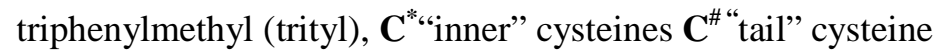


Table S2: Microwave Conditions for Coupling/Deprotection ${ }^{13-14}$

\begin{tabular}{|l|l|l|l|}
\hline & Power (Watts) & Temperature $\left({ }^{\circ} \mathrm{C}\right)$ & Time (s) \\
\hline $\begin{array}{l}\text { Single Coupling (all } \\
\text { amino acids except } \\
\text { arginine) } \\
30 \text { Minute coupling }\end{array}$ & 0 & 25 & 900 \\
\cline { 2 - 4 } $\begin{array}{l}\text { Arginine Coupling } \\
60 \quad \text { minutes (double } \\
\text { coupling) }\end{array}$ & 35 & 73 & 900 \\
\hline De-protection & 40 & 25 & 2700 \\
\hline Total Run Time & 26 hours & 73 & 900 \\
\hline
\end{tabular}

\section{On Resin Cyclization ${ }^{15,18-19}$}

To avoid side-reactions, cyclization was performed on resin with the N-terminal amino acid still protected with the FMoc group. A disulphide bond was formed between two the cysteine residues $\left(\mathrm{C}^{*}\right)$ at positions 2 and 15, by iodine-oxidation. The details of the procedure are as follows:

1. The resin was swelled with DMF (3x).

2. Mmt was cleaved from the "inner" cysteines using $1 \%$ TFA.

3. The peptide was oxidized with $\mathrm{I}_{2}(10 \mathrm{eq})$ in DMF for 1.5 hours, with gentle stirring at room temperature.

4. The resin was washed thoroughly with DCM (dichloromethane) (5x), $\mathrm{CCl}_{4}(5 \mathrm{x})$ and DMF (10x) to remove iodine.

5. Peptides were cleaved from the resin and the remaining side chain protecting groups removed with $1 \%$ TIS(tri-isopropylsilane) $+1 \%$ thioanisole $+1 \% 1,2$ ethanedithiol $+95 \%$ TFA in DCM for 2 hours. $^{13}$

The peptides were purified on a Younglin ACME 9000 instrument using an ACE C-18 reverse phase semi-preparative High Performance Liquid Chromatography (HPLC) column and mass spectra were obtained on a Bruker ESI-QTOF mass spectrometer and Shimadzu Prominence LC-MS System. The purified peptide was lyophilized using a VirTis benchtop $\mathrm{K}$ freeze dryer and stored at $-20^{\circ} \mathrm{C}$ until use. 


\section{Linker Conjugation}

SPDP is an amine-sulfhydryl crosslinking molecule that has an amine reactive portion ( $N$ hydroxysuccinimide (NHS) ester) and a sulfhydryl-reactive portion (2-pyridyldithio group)

The 2-pyridyldithio group reacts optimally with sulfhydryl- containing molecules, such as cysteine, between $\mathrm{pH} 7$ and 8 . The cysteine at the end of the "AAC" tail of the cyclic peptide was conjugated to SPDP as follows:

$25 \mu \mathrm{L}$ of $20 \mathrm{mM}$ SPDP solution was added to $2 \mathrm{mg}$ cyclic peptide dissolved in $1 \mathrm{~mL}$ of PBS. The mixture was incubated for 30 minutes at room temperature. Excess SPDP was then removed by Sephadex G-25 PD-10 desalting column (GE Healthcare Life Sciences, Pittsburgh, Pennsylvania, USA). Then the solution was added to $1 \mathrm{~mL}$ polyethyleneimine coated gold nanoparticle and incubated overnight to allow conjugation of the peptide-SPDP with the amine side chains of polyethyleneimine via the NHS ester of SPDP. The excess peptide-SPDP was removed by repeated centrifugation and washing with PBS. 


\section{Appendix C: Aggregation and its quantification by Light Microscopy and Photographic Software}

Nanoparticle aggregation is often overlooked or understated; however, the complexity of the mechanisms and factors involved, and the importance of the phenomenon, are now being recognised. ${ }^{1}$ In this study, it is postulated that aggregation occurs whenseveral nanoparticles are attracted to the same polyethyleneimine molecule. ${ }^{20}$ The proposed mechanism is shown in Figure S3.

Aggregation may be detected by colour change, spectrophotometry, dynamic light scattering, nanoparticle tracking analysis ${ }^{21}$ and microscopy (electron or light). In this study, light microscopy was found to be a convenient method to quantify aggregation since it is quick, inexpensive, can be performed in situ (without requiring transfer of the sample to a cuvette), does not destroy or disturb the sample (so that incubation can be continued and the measurement repeated at varying points of time).It requires a small sample volume and has no limit in terms of size and shape of the particles. Moreover, it is unlikely that particles larger than 1 micron will be internalised, and 1 micron is incidentally the approximate maximum resolution of a light microscope (at 100x magnification). Additionally, it is the total number of nanoparticles contained within the sum of all aggregates that is of concern (since these may no longer be taken up), rather than the number of aggregates, (a large number of small aggregates may contain the same number of nanoparticles as a small number of large aggregates). The number of nanoparticles contained within an aggregate is directly proportional to its total volume. Furthermore, if the assumption is made that aggregates are formed and orientated randomly in three dimensional space, then the surface area is directly proportional to the volume of the aggregate and hence to the total the number of nanoparticles contained within it. Therefore, a two dimensional photograph of aggregates under light microscopy will be a good approximation of the total number of aggregated gold nanoparticles.

It must be noted that the assumption that number of particles within an aggregate is linearly proportional to its size (and mass) cannot be taken for granted, and is certainly not true if aggregates are formed as self-similar (mass-fractal) structures, in which case power-law (rather than linear) relationships are characteristic. ${ }^{1}$ Nevertheless, in the absence of certainty about the exact mechanism of aggregation (and the effect of "external forces"), such assumptions can only be tested by quantification within a defined experimental setup. Findings may certainly not be extrapolated to experimental setups where the conditions are different, even if such differences are seemingly minor. 

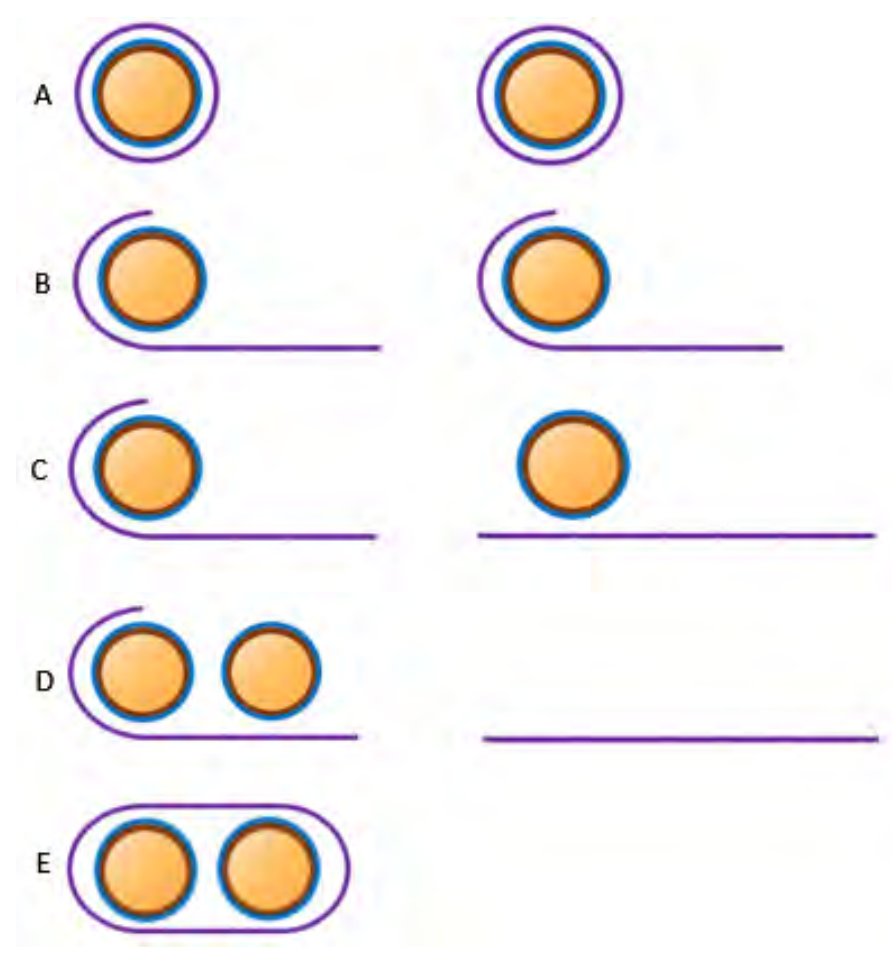

\section{Legend}

Negatively charged gold nanoparticle

Positively charged polyethyleneimine

Figure S3:Aggregation occurs when several nanoparticles are attracted to the same polyethyleneimine molecule. ${ }^{20,22-25}$. Non-aggregated gold nanoparticles coated with polyethyleneimine. Exposure to serum proteins is hypothesised to result in leeching of polyethyleneimine from the surface of nanoparticles ( $B$, C). This results in the disorderly and random association of several $(>1)$ nanoparticles with the same molecule of polyethyleneimine, resulting in the formation of aggregates $(D, E)$. The polyethyleneimine used in this paper is branched but is shown here as a linear molecule for simplicity. The aggregates shown here ( $D$ and $E$ ) consists of 2 nanoparticles (a doublet); the number of nanoparticles contained in aggregates described in this paper is unknown, but is most likely much larger and variable. 
Quantification of aggregation by light microscopy was performed as follows

1. Aliquots of the nanoparticle solutions weredispensed in triplicate into the well of a clear flatbottomed microtiter plate.

2. The wells were then viewed under a Leica DMIL light microscope (Leica, Wetzlar, Germany) at 200x magnification.

3. Light intensity and course focus were fixed during observation to avoid well to well variation in viewing conditions.

4. Representative images were captured on a Zeiss Axiocam 105 camera (Carl Zeiss, Oberkochen, Germany).

5. The images were imported into Image $\mathrm{J}$ software in an 8-bit grayscale format.

6. The black:white threshold was adjusted by the maximum entropy method. ${ }^{26}$ The choice of threshold adjustment method was made empirically. The method that most accurately represented the percentage of black pixels that corresponded to visual approximation was chosen. The important point is that data using different methods cannot be compared. Therefore, the method, once chosen, was used for all experiments in which data was compared.

7. The number of black pixels (representing aggregated nanoparticles) was enumerated by Image $J$ software and expressed as a percentage of the total number of pixels.

8. In order to generate a standard curve, serial, 2-fold dilutions of a highly aggregated gold nanoparticle solution were made with PBS, in the wells of a clear, flat bottom microtiter plate. The solution was thoroughly mixed at each step to ensure that aggregated nanoparticles were likewise diluted. Dilutions were prepared in triplicate. Photographs were taken of each dilution and the percentage black pixels was determined as described above (steps 1-7). The percentage black pixels was plotted against serial dilutions of the aggregated gold nanoparticle (log transformed to base 2) (Figure S4). The method showed excellent correlation ( $r=0.99)$ between percentage black pixels vs. actual aggregation of serially diluted aliquots in the range of 0.3 to 50 \% aggregation. Typical images are shown in Figure S5. 


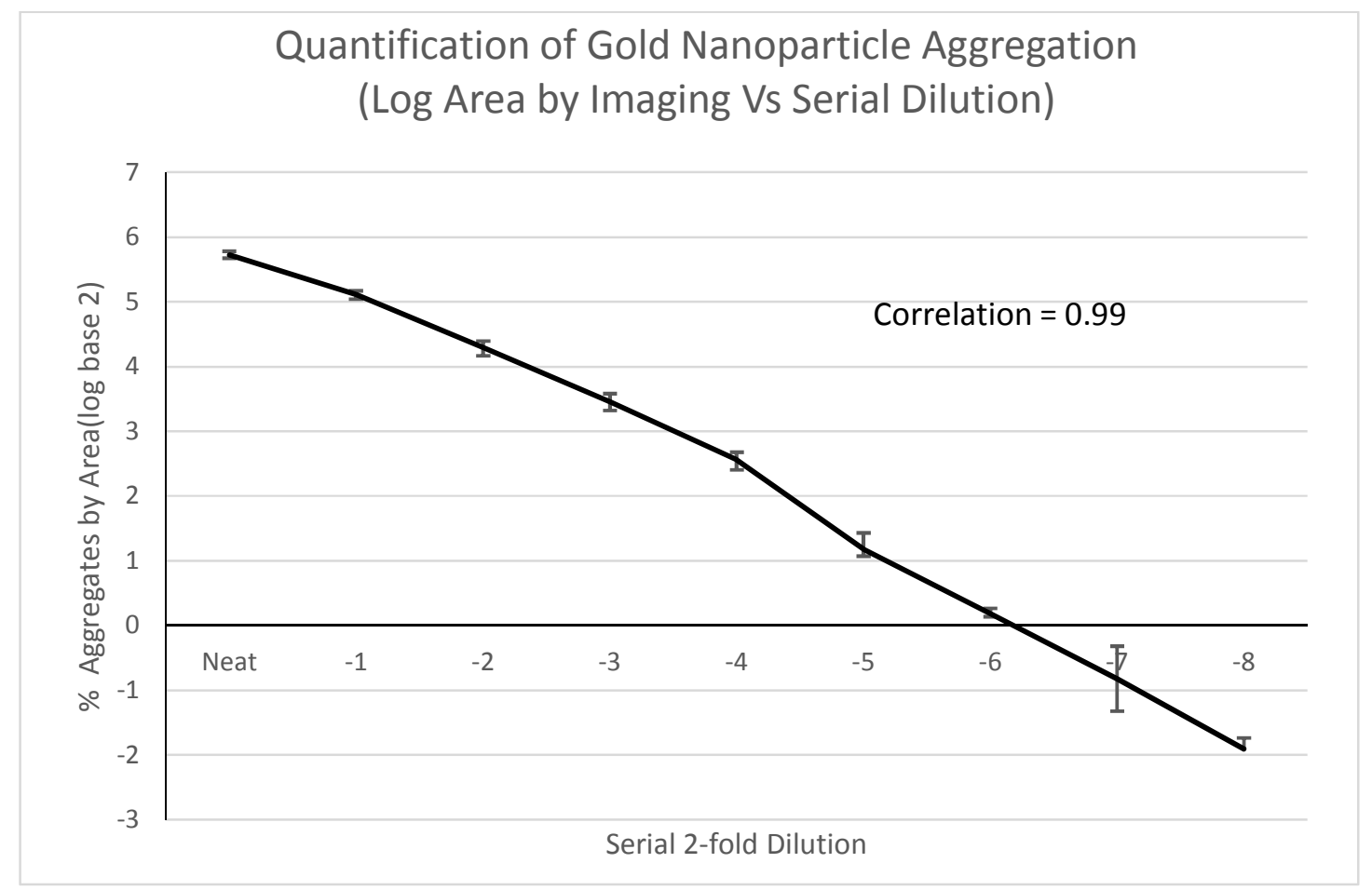

Figure S4:Graph showing linear relationship between serially diluted aggregated gold nanoparticles and photographically determined aggregation (expressed as a percentage of black pixels) 


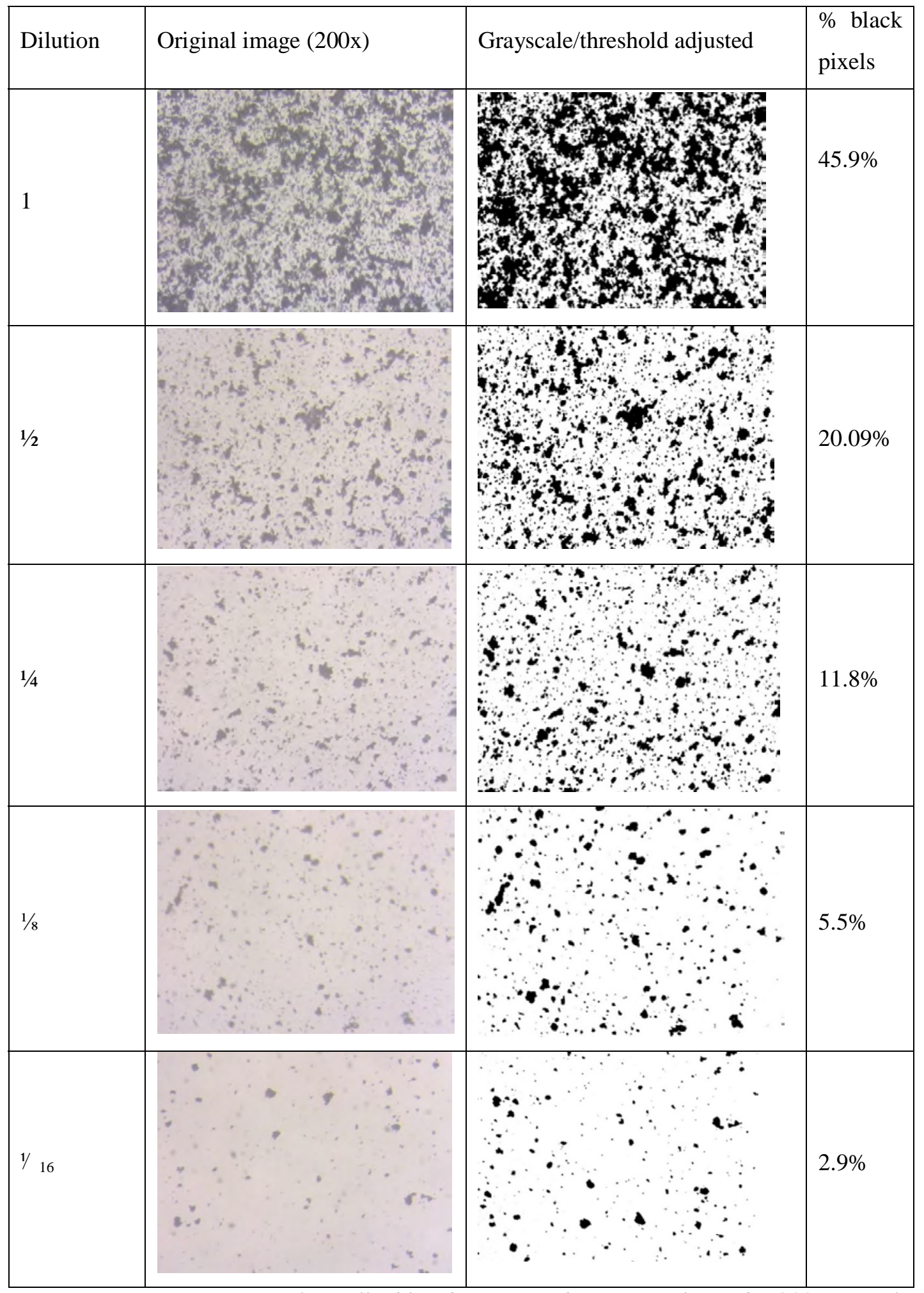

Figure S5:Representative images of serially diluted aggregated nanoparticles under 200x magnification, the corresponding 8-bit grayscale images with the black-white threshold adjusted by the maximum entropy method, and the percentage black pixels (as determined by ImageJ software). 


\section{Appendix D: SPDP Loading}

The loading (SPDP linker molecules per nanoparticle) was determined by measuring the concentration of pyridine-2-thione which is released from the surface of the gold nanoparticle when exposed to the reducing agent dithiothreitol (DTT).

The assay is performed as follows:

1. SPDP was conjugated to the PEGylated nanoparticle as described in the synthesis section. For the purposes of this experiment, the volume of SPDP and PEGylated gold nanoparticle used in the reaction was increased (without altering the concentration of the reactants) so that a "measurable" concentration of pyridine-2-thione would be released at the end of the assay. A "measurable" concentration of pyridine-2-thione was defined by an absorbance reading at least 3 standard deviations greater than the "Blank". In a typical experiment, $20 \mathrm{~mL}$ of reaction product (i.e. a mixture of $10 \mathrm{~mL}$ SPDP + $10 \mathrm{~mL}$ GNP-PEG), re-suspended after final centrifugation to a volume of $1 \mathrm{~mL}$, was sufficient. It is important that the volume of the reaction mixtures be adjusted, rather than the concentration of SPDP. SPDP is poorly soluble in water; increasing the concentration excessively results in precipitation and spurious results.

2. At the end of the reaction described in step one, the solution was repeatedly washed by centrifugation and resuspension in PBS-Tween-20 ${ }^{\mathrm{TM}}(0.01 \%)$ to remove excess SPDP. A $500 \mu \mathrm{L}$ aliquot of the supernatant after the last spin was tested for the presence of SPDP using the pyridine-2-thione assay (as described in the steps below). An absorbance value of $<0.01$ (or a reading within 1 standard deviation of the "Blank") was regarded as suitable. Typically, 4 washes were required for adequate removal of excess SPDP.

3. After the last wash, the gold nanoparticle solution (GNP-PEG-SPDP) was re-suspended in $1 \mathrm{~mL}$ PBS/Tween, vortexed thoroughly, and then divided into 2 x $500 \mu \mathrm{L}$ aliquots.

4. 1 aliquot of the gold nanoparticle solution was mixed with $5 \mu \mathrm{L}$ PBS (labelled GNP-PBS); the other aliquot of the gold nanoparticle solution (labelled GNP-DTT) was mixed with $5 \mu \mathrm{L}$ DTT (15 mg/mL).

5. The mixed solutions were incubated at room temperature for 15 minutes.

6. After exactly 15 minutes, the aliquots were centrifuged until the supernatant was clear and the gold nanoparticle formed a distinct pellet.

7. The absorbance at 343nm of the supernatant of each aliquot was recorded in triplicate. 
8. The difference in absorbance was calculated as follows:

Difference in absorbance $=$ GNP-DTT $-($ GNP-PBS $)$

Where GNP-DTT = mean absorbance of supernatant of GNP solution treated with DTT

GNP-PBS = mean absorbance of supernatant of GNP solution treated with PBS

PBS-TWEEN was read as "Blank".

9. The molar concentration of the SPDP was then calculated as follows:

Molar concentration (in $\mathrm{mM})=$ difference in absorbance $\div\left(8.08 \mathrm{mM}^{-1} \mathrm{~cm}^{-1} \mathrm{x}\right.$ path-length in $\left.\mathrm{cm}\right)$, where $8.08 \times 10^{-3} \mathrm{M}^{-1} \mathrm{~cm}^{-1}$ is the“extinction coefficient" or molar absorptivity for pyridine-2thione at 343 nmand the path-length, when using the BioSpec Nano in the 0.7 mm mode.

In a typical experiment, the molar concentration of pyridine-2-thione in the final $1 \mathrm{~mL}$ aliquot was found to be $407 \mu \mathrm{M}$ or $407000 \mathrm{nM}$ (based on mean absorbance difference of 0.23 units). The concentration of gold nanoparticle in the same aliquot was $20 \mathrm{nM}$ (as determined by absorbance measurements). ${ }^{27}$ Therefore, each nanoparticle was decorated with an average of (407 $000 \div 20=$ ) 20350 SPDP linker molecules (or $\sim 2.6$ SPDP molecules per $\mathrm{nm}^{2}$ nanoparticle surface area). 


\section{Appendix E: Details of the Method to Determine RNA Concentration to Calculate Loading and Uptake}

It was necessary to measure the concentration of RNA to allow for the determination of RNA loading per nanoparticle and to assess cellular uptake (as an alternative to flow cytometry and epifluorescent microscopy). The RNA was synthesised with a fluorescein tag at the 3' end, which allows for quantification by generation of a standard curve of fluorescence. This was measured as relative fluorescence units (RFU vs. RNA concentration and determined by absorbance and serial dilutions; a representative graph is presented in Figure S6. Fluorescence is significantly more sensitive than absorbance for RNA quantification. The approximate lower limit for absorbance-based quantification using the Biospec Nano is given as $15 \mathrm{ng} / \mu \mathrm{L}$ of ds DNA based on the $0.7 \mathrm{~mm}$ path length method. This equates to a limit of quantification of RNA used in this experiment to approximately $2.8 \mu \mathrm{M}$. By contrast, measurement by fluorescence (using the method described in this section) is at least 1000x more sensitive which allows quantification in the nanomolar range (from as low as $1 \mathrm{nM}$ ).

The concentration of the stock RNA (which was synthesised in the micromolar scale) was determined by UV spectroscopy on the BioSpec Nano. An adjustment was made for the absorbance of fluorescein using the on-board software. The ratio of absorbance at $260 \mathrm{~nm}$ to absorbance at $280 \mathrm{~nm}$ allows for the determination of the concentration of RNA using the Beer-Lambert Law. ${ }^{28}$ The concentration of a typical aliquot of RNA using this method was determined to be $888 \mathrm{ng} / \mu \mathrm{L}$. The molecular weight of the RNA = $5315 \mathrm{~g} / \mathrm{mol}$ or $5315 \mathrm{ng} / \mathrm{nmol}$. Therefore, the concentration of the RNA $=888 / 5315 \mathrm{nmol} / \mu \mathrm{L}=167 \mu \mathrm{mol} / \mathrm{L}$ $=167 \mu \mathrm{M}$.

The concentration was adjusted to $10 \mu \mathrm{M}$ by addition of RNAse free deionised water. Eight serial 10 fold dilutions were made, in triplicate, in a black microtiter plate and the fluorescence read in the Glomax Multimode Detection System using the Blue filter (Excitation 490nm/Emission 510-570nm). The readings were log transformed (base 10) and plotted in Excel $^{\mathrm{TM}}$ and the RNA concentration then determined by linear extrapolation on the logarithmic scale.

For determination of RNA loading, the concentration of released RNA was determined (e.g. 1200nM) and divided by the concentration of gold nanoparticle (e.g. $1.14 \mathrm{nM}$ ) to yield the number of strands of RNA per gold nanoparticle (e.g. 1053).

To determine uptake, the concentration of RNA was similarly determined in the supernatant following cell lysis and centrifugation. The concentration of RNA (e.g. $75 \mathrm{nM}$ ) was then used to calculate the 
number of nanomoles of RNA per million cells (e.g. $7.5 \times 10^{-5}$ nmoles per million cells) which corresponds to 45000 strands of RNA per cell.

The limit of detection of RNA uptake per cell was calculated based on the lower limit of detection of RNA of $1 \mathrm{nM}$, corresponding to a Relative Fluorescence Units $(\mathrm{RFU})=5.3$. Moreover, RFU values $<7$ (i.e. falling within 2 standard deviations away from the mean) are likely due to instrument "noise" rather than biological factors. Therefore, only readings $>7$ RFU above the mean were regarded as significant. The standard deviation of the fluorescence measurements was calculated by reading 30 wells of a "blank" plate.

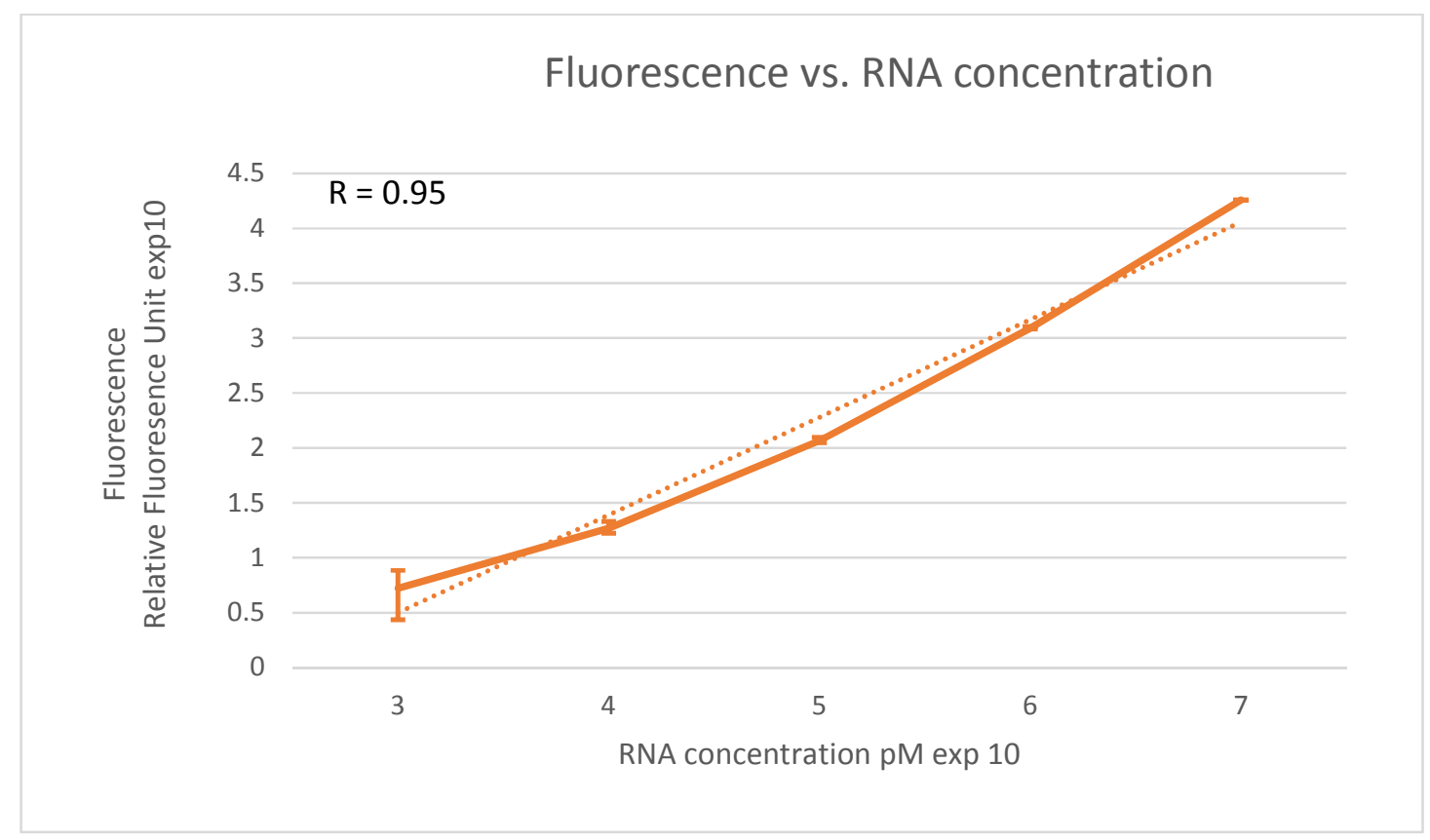

Figure S6:Graph showing log-linear relationship between RNA concentration (in pM) and relative fluorescence units (dimensionless) over a wide range (from about $1 \mathrm{nM}$ to $10 \mu \mathrm{M}$ ). Fluorescence readings of RNA below 1 nM concentration were close to zero and are not shown. The dotted line is the linear trend line. 


\section{Appendix F: Optimisation}

A series of experiments were carried out, in which the synthesis procedure and uptake conditions were varied, in an attempt to improve aggregation and uptake.

\section{Size of GNP}

In a previous study to determine the effect of nanoparticle size on uptake into Hela cells, nanoparticles with diameter $30-50 \mathrm{~nm}$ were taken up more readily than smaller or larger particles. ${ }^{29}$ Therefore, the assumption was made that the nanoparticles used in this paper (30-40nm) would achieve similar results. Nevertheless, the synthesis procedure (as described in the Synthesissection) was repeated with nanoparticles of diameter $15 \mathrm{~nm}$, without significant improvement in aggregation and uptake. Nanoparticles of size $15 \mathrm{~nm}$ were synthesised using the same method as described for $30-40 \mathrm{~mm}$ gold nanoparticles, except that the amount of sodium citrate was doubled. ${ }^{30}$ The concentration of reagents for each of the subsequent steps was adjusted to take into account the surface area of $15 \mathrm{~nm}$ particles.

\section{RNA concentration}

It is important to optimise the conjugation of the RNA to the gold nanoparticle, since synthetic RNA is expensive and produced in small quantities (usually in the nanomolar or micromolar scale). The proportion of RNA that binds to the surface of the nanoparticle (as opposed to the RNA that fails to bind) was determined by measuring the concentration of the RNA in the supernatant pre and post reaction.

In a typical reaction, only $1.2 \mu \mathrm{M}$ of $15 \mu \mathrm{M}$ (i.e. 8\%) of RNA added per reaction, conjugated to the gold nanoparticle. The rest (92\%) of the RNA remains in the supernatant. This was confirmed by measuring the concentration of the RNA in the supernatant, both by fluorescence and absorbance. Lee et al. do not explicitly determine the proportion of RNA that conjugates to the GNP. ${ }^{31}$ However, they provide sufficient data for the calculation to be made. Based on reaction of $15 \mu \mathrm{M}$ RNA and 30 nM GNP in 400 $\mu \mathrm{L}$ buffer and resulting $~ 30$ strands of RNA per particle, the proportion of RNA conjugated to the surface of the GNP was calculated to be 6\%. Therefore, the efficiency of RNA conjugation in our experiments is in keeping with that of Lee et al. ${ }^{31}$ Increasing the concentration of RNA did not improve the loading.

\section{Polyethyleneimine concentration}

The concentration of polyethyleneimine optimised for coating in a previous study was $1 \mathrm{mg}$ polyethyleneimine per $\mathrm{mL}^{23}$ It was not deemed viable to significantly reduce the concentration of 
polyethyleneimine since a positively charged nanoparticle was required to facilitate cellular uptake. The zeta potential of the nanoparticle was only $+13.5 \mathrm{mV}$, even when synthesised with polyethyleneimine at 1 $\mathrm{mg} / \mathrm{mL}$ (compared to a zeta potential of $\sim+60 \mathrm{mV}$ achieved by a layer-by-layer approach. ${ }^{23}$ Increasing the concentration of polyethyleneimine (up to $10 \mathrm{mg} / \mathrm{mL}$ ) resulted in an increase in zeta potential ( 23.6 $\mathrm{mV})$. However, the aggregation of the nanoparticleswas exacerbated and there was no improvement in the uptake (as determined by flow cytometry). Therefore, the optimal concentration of $1 \mathrm{mg} / \mathrm{mL}$, as described by Elbakry et al. ${ }^{23}$ was used in subsequent experiments.

\section{Treatment Conditions}

Uptake was optimal with treatment duration of 24 hours (compared to 1, 2 hours and 4 hours). The use of serum-free OptiMEM ${ }^{\mathrm{TM}}$ media did not improve uptake (as determined by epifluorescent microscopy). The experiments were repeated with an adherent cell line (a human cervical epithelial carcinoma cell line (Hela), obtainedthrough the NIH AIDS Reagent Program, Division of AIDS, NIAID, NIH: HeLa CD4(HT4-6C) from Dr Bruce Chesebro). ${ }^{32-33}$ However, the nanoparticle was not taken up by this cell line (as determined by flow cytometry). 


\section{References}

1. Moore, T. L.; Rodriguez-Lorenzo, L.; Hirsch, V.; Balog, S.; Urban, D.; Jud, C.; RothenRutishauser, B.; Lattuada, M.; Petri-Fink, A., Nanoparticle colloidal stability in cell culture media and impact on cellular interactions. Chemical Society reviews 2015,44 (17), 6287-305.

2. Giljohann, D. A.; Seferos, D. S.; Daniel, W. L.; Massich, M. D.; Patel, P. C.; Mirkin, C. A., Gold nanoparticles for biology and medicine. Angew Chem Int Ed Engl 2010,49 (19), 3280-94.

3. Sewald, N.; Jakubke, H.-D., Peptide Synthesis. Wiley-VCH Verlag GmbH \& Co. KGaA: 2009; p 175-315.

4. Monnet, C.; Laune, D.; Laroche-Traineau, J.; Biard-Piechaczyk, M.; Briant, L.; Bes, C.; Pugniere, M.; Mani, J. C.; Pau, B.; Cerutti, M.; Devauchelle, G.; Devaux, C.; Granier, C.; Chardes, T., Synthetic peptides derived from the variable regions of an anti-CD4 monoclonal antibody bind to CD4 and inhibit HIV-1 promoter activation in virus-infected cells. $J$ Biol Chem 1999,274 (6), 3789-96.

5. Bes, C.; Briant-Longuet, L.; Cerruti, M.; De Berardinis, P.; Devauchelle, G.; Devaux, C.; Granier, C.; Chardes, T., Efficient CD4 binding and immunosuppressive properties of the 13B8.2 monoclonal antibody are displayed by its CDR-H1-derived peptide CB1. FEBS Lett 2001,508 (1), 67-74.

6. Bes, C.; Briant-Longuet, L.; Cerutti, M.; Heitz, F.; Troadec, S.; Pugniere, M.; Roquet, F.; Molina, F.; Casset, F.; Bresson, D.; Peraldi-Roux, S.; Devauchelle, G.; Devaux, C.; Granier, C.; Chardes, T., Mapping the paratope of anti-CD4 recombinant Fab 13B8.2 by combining parallel peptide synthesis and site-directed mutagenesis. J Biol Chem 2003,278 (16), 14265-73.

7. Albericio, F., Developments in peptide and amide synthesis. Curr Opin Chem Biol 2004,8 (3), 211-21.

8. Boschek, C. B.; Apiyo, D. O.; Soares, T. A.; Engelmann, H. E.; Pefaur, N. B.; Straatsma, T. P.; Baird, C. L., Engineering an ultra-stable affinity reagent based on Top7. Protein Eng Des Sel 2009,22 (5), 325-32.

9. $\quad$ Wellings, D. A.; Atherton, E., Standard Fmoc protocols. Methods Enzymol 1997,289, 44-67.

10. Fields, G., Solid-phase peptide synthesis. Molecular Biomethods Handbook 1998, 527-545.

11. Amblard, M.; Fehrentz, J. A.; Martinez, J.; Subra, G., Methods and Protocols of modern solid phase peptide synthesis. Mol Biotechnol 2006,33 (3), 239-254.

12. Rapley, R.; Walker, J. M., Molecular Biomethods Handbook. 2nd ed.; Humana Press: Totowa, NJ, 2008; p xx, 1124 p.

13. Muthusamy, K.; Albericio, F.; Arvidsson, P. I.; Govender, P.; Kruger, H. G.; Maguire, G. E.; Govender, T., Microwave assisted SPPS of amylin and its toxicity of the pure product to RIN-5F cells. Biopolymers 2010,94 (3), 323-30.

14. Pietersen, L. K.; Govender, P.; Kruger, H. G.; Maguire, G. E. M.; Wesley-Smith, J.; Govender, T., Peptide Functionalised Gold Nanoparticles: Effect of Loading on Aggregation and Proteolysis. International Journal of Peptide Research and Therapeutics 2010,16 (4), 291-295.

15. Galanis, A. S.; Albericio, F.; Grotli, M., Enhanced microwave-assisted method for on-bead disulfide bond formation: synthesis of alpha-conotoxin MII. Biopolymers 2009,92 (1), 23-34.

16. Guy, C. A.; Fields, G. B., Trifluoroacetic acid cleavage and deprotection of resin-bound peptides following synthesis by Fmoc chemistry. Methods Enzymol 1997,289, 67-83.

17. Fields, G. B., Methods for removing the Fmoc group. Methods Mol Biol 1994,35, 17-27.

18. Andreu, D.; Albericio, F.; Sole, N. A.; Munson, M. C.; Ferrer, M.; Barany, G., Formation of disulfide bonds in synthetic peptides and proteins. Methods Mol Biol 1994,35, 91-169. 
19. Chen, L.; Annis, I.; Barany, G., Disulfide bond formation in peptides. Curr Protoc Protein Sci 2001,Chapter 18, Unit18 6.

20. Ariyawansa, T.; Pullman, H.; Amiji, M. M.; Bhavsar, M. M. D. The Development of Multifunctional Nanoparticles for Simultaneous Fluorescence Imaging and Gene Delivery. http://web.mit.edu/rsi/www/pdfs/papers/2006/2006-thilini.pdf.

21. James, A. E.; Driskell, J. D., Monitoring gold nanoparticle conjugation and analysis of biomolecular binding with nanoparticle tracking analysis (NTA) and dynamic light scattering (DLS). The Analyst 2013,138 (4), 1212-8.

22. Wang, X.; Zhou, L.; Ma, Y.; Li, X.; Gu, H., Control of aggregate size of polyethyleneiminecoated magnetic nanoparticles for magnetofection. Nano Research 2010,2 (5), 365-372.

23. Elbakry, A.; Zaky, A.; Liebl, R.; Rachel, R.; Goepferich, A.; Breunig, M., Layer-by-layer assembled gold nanoparticles for siRNA delivery. Nano Lett 2009,9 (5), 2059-64.

24. Gittins, D. I.; Caruso, F., Tailoring the Polyelectrolyte Coating of Metal Nanoparticles. The Journal of Physical Chemistry B 2001,105 (29), 6846-6852.

25. Schneider, G.; Decher, G., Functional core/shell nanoparticles via layer-by-layer assembly. investigation of the experimental parameters for controlling particle aggregation and for enhancing dispersion stability. Langmuir 2008,24 (5), 1778-89.

26. Rasband, W. Image J, National Institutes of Health: 2016.

27. Haiss, W.; Thanh, N. T. K.; Aveyard, J.; Fernig, D. G., Determination of size and concentration of gold nanoparticles from UV-vis spectra. Analytical chemistry 2007,79 (11), 4215-4221.

28. Thermo Fisher Scientific Inc. RNA quantitation is an important and necessary step prior to most RNA analysis methods. http://www.webcitation.org/6kdWpl2gs.

29. Chithrani, B. D.; Ghazani, A. A.; Chan, W. C., Determining the size and shape dependence of gold nanoparticle uptake into mammalian cells. Nano Lett 2006,6 (4), 662-8.

30. Kanaras, A. G.; Wang, Z.; Hussain, I.; Brust, M.; Cosstick, R.; Bates, A. D., Site Specific Ligation of DNA Modified Gold Nanoparticles Activated by the Restriction Enzyme StyI. Small 2007,3 (1), 67-70.

31. Lee, J. S.; Green, J. J.; Love, K. T.; Sunshine, J.; Langer, R.; Anderson, D. G., Gold, poly(betaamino ester) nanoparticles for small interfering RNA delivery. Nano Lett 2009,9 (6), 2402-6.

32. Chesebro, B.; Buller, R.; Portis, J.; Wehrly, K., Failure of human immunodeficiency virus entry and infection in CD4-positive human brain and skin cells. Journal of Virology 1990,64 (1), 21521.

33. Chesebro, B.; Wehrly, K., Development of a sensitive quantitative focal assay for human immunodeficiency virus infectivity. Journal of Virology 1988,62 (10), 3779-88. 